\title{
Characterization of breast calcification types using dual energy X-ray method
}

This content has been downloaded from IOPscience. Please scroll down to see the full text.

Download details:

IP Address: 128.41.35.156

This content was downloaded on 14/08/2017 at 14:31

Manuscript version: Accepted Manuscript

Martini et al

To cite this article before publication: Martini et al, 2017, Phys. Med. Biol., at press: https://doi.org/10.1088/1361-6560/aa8445

This Accepted Manuscript is: (c) 2017 Institute of Physics and Engineering in Medicine

During the embargo period (the 12 month period from the publication of the Version of Record of this article), the Accepted Manuscript is fully protected by copyright and cannot be reused or reposted elsewhere.

As the Version of Record of this article is going to be / has been published on a subscription basis, this Accepted Manuscript is available for reuse under a CC BY-NC-ND 3.0 licence after the 12 month embargo period.

After the embargo period, everyone is permitted to copy and redistribute this article for non-commercial purposes only, provided that they adhere to all the terms of the licence https://creativecommons.org/licences/by-nc-nd/3.0

Although reasonable endeavours have been taken to obtain all necessary permissions from third parties to include their copyrighted content within this article, their full citation and copyright line may not be present in this Accepted Manuscript version. Before using any content from this article, please refer to the Version of Record on IOPscience once published for full citation and copyright details, as permission will likely be required. All third party content is fully copyright protected, unless specifically stated otherwise in the figure caption in the Version of Record.

When available, you can view the Version of Record for this article at: http://iopscience.iop.org/article/10.1088/1361-6560/aa8445 


\title{
Characterization of breast calcification types using dual energy X-ray method
}

\author{
N Martini' ${ }^{1}$, V Koukou', G Fountos ${ }^{2}$, C Michail ${ }^{2}$, A Bakas ${ }^{3}$, I \\ Kandarakis $^{2}$, R Speller ${ }^{4}$, G Nikiforidis ${ }^{1}$ \\ 1 Department of Medical Physics, Medical School, University of \\ Patras, 26500 Patras, Greece \\ ${ }^{2}$ Radiation Physics, Materials Technology and Biomedical Imaging \\ Laboratory, Department of Biomedical Engineering, Technological \\ Educational Institute of Athens, Egaleo, 12210 Athens, Greece \\ ${ }^{3}$ Department of Radiology \& Radiation Therapy, Faculty of Health \\ and Caring Professions, Technological Educational Institution of \\ Athens, 12210 Athens, Greece \\ ${ }^{4}$ Department of Medical Physics and Bioengineering, University \\ College London, Malet Place, Gower Street, London WC1E 6BT, UK \\ E-mail: George Fountos, gfoun@teiath.gr
}

\begin{abstract}
Calcifications are products of mineralization whose presence is usually associated with pathological conditions. The minerals mostly seen in several diseases are calcium oxalate $\left(\mathrm{CaC}_{2} \mathrm{O}_{4}\right)$, calcium carbonate $\left(\mathrm{CaCO}_{3}\right)$ and hydroxyapatite (HAp). Up to date, there is no in-vivo method that could discriminate between minerals. To this aim, a dual energy X-ray method was developed in the present study. An analytical model was implemented for the determination of the Calcium/Phosphorus mass ratio $\left(\mathrm{m}_{\mathrm{Ca}} / \mathrm{m}_{\mathrm{P}}\right)$. The simulation was carried out using monoenergetic and polyenergetic X-rays and various calcification thicknesses (100 to $1000 \mu \mathrm{m})$ and types $\left(\mathrm{CaC}_{2} \mathrm{O}_{4}, \mathrm{CaCO}_{3}, \mathrm{HAp}\right)$. The experimental evaluation of the method was performed using the optimized irradiation conditions obtained from the simulation study. X-ray tubes, combined with energy dispersive and energy integrating (imaging) detectors, were used for the determination of the $\mathrm{m}_{\mathrm{Ca}} / \mathrm{m}_{\mathrm{P}}$ in phantoms of different mineral types and thicknesses. Based on the results of the experimental procedure, statistical significant difference was observed between the different types of minerals when calcification thicknesses were $300 \mu \mathrm{m}$ or higher.
\end{abstract}

Keywords: Dual energy, calcifications, calcium/phosphorus ratio

\section{Introduction}

Breast cancer is the most common cause of cancer deaths, accounting for approximately $16 \%$ in adult women (WHO 2008). Early detection is important for patients' treatment and 
recovery. Preliminary signs of masses and microcalcifications are important indicators of breast cancer (Roberts et al 1995, Kappadath and Shaw 2004, 2005). A significant percentage of non-palpable breast cancers $(30-50 \%)$ are detected only due to the appearance of microcalcifications in a mammogram (Cox and Morgan 2013). Several studies have suggested that the presence of calcifications may also be of biological significance, while its type may indicate malignancy and disease state (Radi 1989, Morgan et al 2001, 2005).

Microcalcifications of the breast were firstly described as calcium deposits within the breast tissue (Leborgne 1951). The three main compositions described in literature are hydroxyapatite (Hap), calcium oxalate $\left(\mathrm{CaC}_{2} \mathrm{O}_{4}\right)$ and calcium carbonate $\left(\mathrm{CaCO}_{3}\right)$ (FandosMorera et al 1988, Chen et al 2008). Microcalcifications are divided into Type I and Type II. Type I calcifications are composed of calcium oxalate $\left(\mathrm{CaC}_{2} \mathrm{O}_{4}\right)$, and are associated with benign lesions of the breast or at most non-invasive lobular carcinoma in situ (Busing et al 1981, Frappart et al 1986). Type II calcifications are composed of calcium phosphate, mainly hydroxyapatite (HAp), and are associated with malignant breast conditions (Haka et al 2002) including carcinomas (Frappart et al 1984). Furthermore, calcifications composed of calcium carbonate $\left(\mathrm{CaCO}_{3}\right)$ are associated with benign lesions of the breast (Fandos-Morera et al 1988, Baker et al 2007). It is often the presence of Type II calcifications that leads to further investigations (Baker et al 2010, Kerssens et al 2010), and they are estimated to occur two to three times more frequently than Type I (Haka et al 2002).

Mammography is considered as the most reliable method in detection of breast calcifications (Haka et al 2002). A major limitation in mammography is the low contrast between glandular and pathologic tissue (Johns and Yaffe 1987, Byng et al 1998), which have similar composition. Dual energy techniques (DE) are able to cancel out the tissue background structures and highlight specific lesions (Taibi et al 2003, Kappadath and Shaw 2004, 2005, 2008, Chen et al 2013, Del Lama 2016, 2016a, Koukou et al 2017). However, both mammography and DE techniques are not able to yield information about the chemical composition of calcifications and help in classifying benign and malignant lesions. Previous noninvasive investigations, using Raman spectroscopy, discriminated malignant and benign lesions in penetration depths from 0.96 to $27 \mathrm{~mm}$ (Baker et al 2007, Matousek and Stone 2007, Stone et al 2007, Stone and Matousek 2008, Matousek and Stone 2013). More recently, a method using X-ray phase-contrast imaging was proposed, based on the absorption and small-angle scattering signals of the different types of microcalcifications (Wang et al 2014). In the present study a dual energy method was developed for the characterization of calcification minerals, based on the determination of Calcium/Phosphorus mass ratio ( $\mathrm{m}_{\mathrm{Ca}} / \mathrm{m}_{\mathrm{P}}$ ). For the minerals, where the Phosphorus is absent, an effective $\mathrm{m}_{\mathrm{Ca}} / \mathrm{m}_{\mathrm{P}}$ was defined. A simulation study, based on analytical modeling was performed using monoenergetic and polyenergetic X-rays in order to obtain the optimized irradiation parameters. Experimental evaluation of the method was followed using photon counting energy dispersive and energy integrating detectors. Results are presented and used to discuss and demonstrate the feasibility of using $\mathrm{m}_{\mathrm{Ca}} / \mathrm{m}_{\mathrm{P}}$ as a parameter for minerals discrimination.

\section{Materials and methods}

\subsection{Simulation studies}


The attenuated intensities for the low-/high-energy beams were calculated through analytical modeling according to the following procedure. Consider that along the monoenergetic X-ray path, a compressed breast of thickness, $\mathrm{T}$, is composed of: (i) 50\% adipose and 50\% glandular tissue (breast tissue) of thickness $t_{b}$ and (ii) a calcification of thickness $t_{c}$ (figure 1).

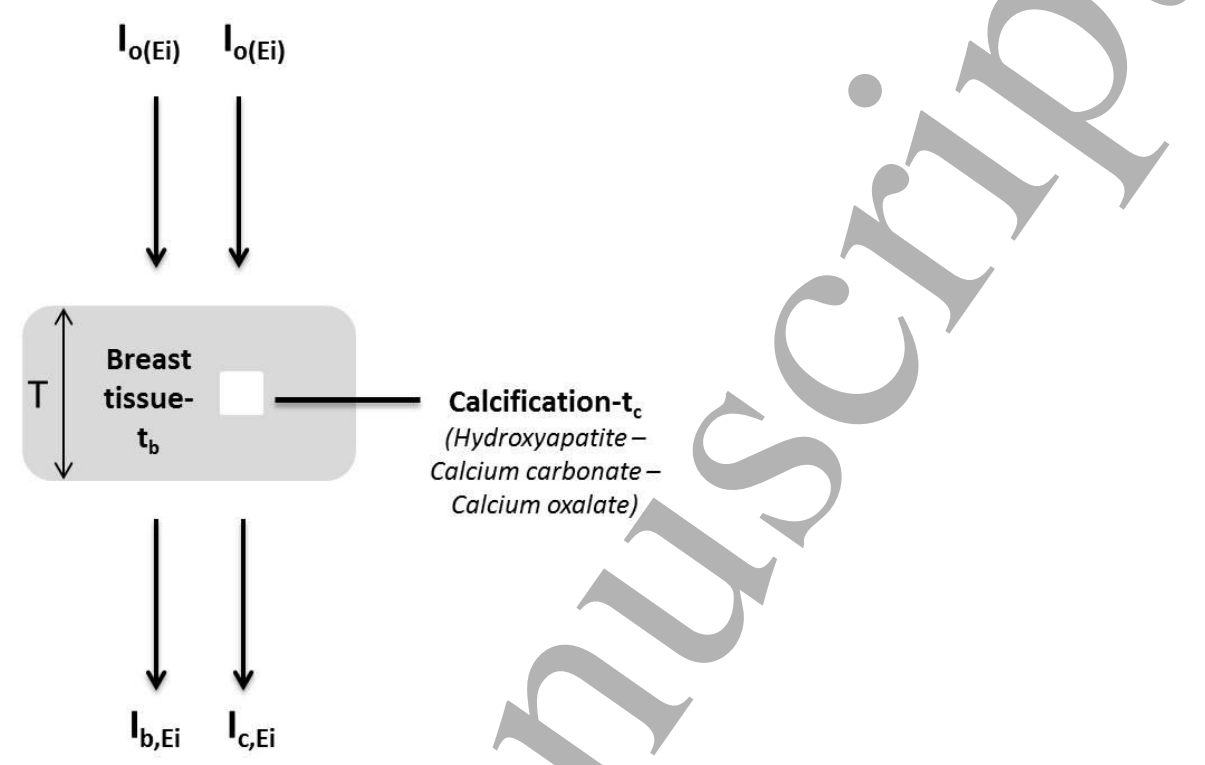

Figure 1. Schematic representation of the procedure for calculating the attenuated intensities $I_{b, E_{i}}$ and $I_{c, E_{i}}$.

Under this consideration, when the X-ray beam passes through only breast tissue, the low/high-energy intensities, $I_{b, E_{l}}$ and $I_{b, E_{h}}$, are calculated by:

$I_{b, E_{i}}=I_{o, E_{i}} e^{-\mu_{b, E_{i} T}} i=l, h$

When the beam passes through the breast tissue and the calcification (minerals), the low/high-energy attenuated intensities, $I_{c, E_{l}}$ and $I_{c, E_{h}}$, can be expressed as:

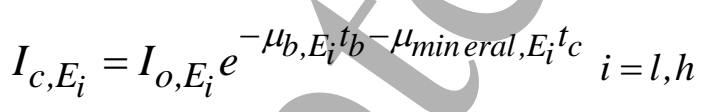

where, $I_{o, E_{l}}$ and $I_{o, E_{h}}$ are the unattenuated low-/high-energy intensities. The energydependent linear attenuation coefficients $\left(\mathrm{cm}^{-1}\right)$ and thicknesses $(\mathrm{cm})$ for breast tissue and minerals are given by $\mu_{b, E_{i}}, \mu_{\text {mineral }, E_{i}}$ and $t_{b}, t_{c}$ respectively.

Three different types of calcifications (minerals) were examined: (i) hydroxyapatite, HAp, $\left(\mathrm{Ca}_{10}\left(\mathrm{PO}_{4}\right)_{6}(\mathrm{OH})_{2}\right)$ with density of $3.18 \mathrm{~g} / \mathrm{cm}^{3}$ (Gong et al 1964), (ii) calcium carbonate $\left(\mathrm{CaCO}_{3}\right)$ with density of $2.93 \mathrm{~g} / \mathrm{cm}^{3}$ (Lemacks et al 2002), and (iii) calcium oxalate $\left(\mathrm{CaC}_{2} \mathrm{O}_{4}\right)$ with density of $2.20 \mathrm{~g} / \mathrm{cm}^{3}$ (Brandan and Ramirez 2006). The minerals are referred to as HAp, $\mathrm{CaCO}_{3}$ and $\mathrm{CaC}_{2} \mathrm{O}_{4}$.

The unattenuated low-/high-energy intensities $I_{o, E_{l}}$ and $I_{o, E_{h}}$ were calculated through the 
entrance surface dose $\left(\mathrm{K}_{\mathrm{a}}\right)$ (Eq. 3) for photon energies between 15 and $70 \mathrm{keV}$ at a resolution of $1 \mathrm{keV}$, following Eq. 4.

$$
\begin{aligned}
& K_{a}(m G y)=8.77 \cdot 10^{-3} \cdot 1.83 \cdot 10^{-6} I_{o, E_{i}} E_{i}\left(\frac{\mu_{e n}}{\rho_{E_{i}}}\right)_{\text {air }} \\
& I_{o, E_{i}}=\frac{K_{a}(m G y)}{8.77 \cdot 10^{-3} \cdot 1.83 \cdot 10^{-6} E_{i}\left(\frac{\mu_{e n}}{\rho_{E_{i}}}\right)_{\text {air }}}
\end{aligned}
$$

where $I_{o, E_{i}}$ is the unattenuated intensity (photons $\left./ \mathrm{mm}^{2}\right)$ at energy $\mathrm{E}_{\mathrm{i} \cdot} \cdot\left(\mu_{\mathrm{en}} / \rho\right)_{\mathrm{E}_{\mathrm{i}}}$ is the X-ray mass energy absorption coefficient of air at energy $E_{i}$ obtained from the literature (Hubbell and Seltzer 1996). $\mathrm{K}_{\mathrm{a}}$ was set at $6 \mathrm{mGy}$ and was split evenly between the low-/high-energy (European Commision 2014).

The attenuated intensities, $I_{b, E_{i}}$ and $I_{c, E_{i}}$, were calculated using mass attenuation coefficients from published data (NIST) (Hubbell and Seltzer 1996). The mass attenuation coefficients were multiplied by the corresponding densities for each material in order to obtain the energy-dependent linear attenuation coefficients. In our method, the input data for the mineral characterization are the attenuated intensities of minerals and the surrounding soft tissue. In practice, for a given attenuated intensity after breast exposure, different mineral types must be distinguished. In order this study to be more realistic, in both computer simulation and experimental studies, for every HAp thickness the equivalent thicknesses of calcite and calcium oxalate were defined resulting in equal attenuation. Warren et al 2013 also concluded in this approach, in order to preserve equivalent attenuation and contrast in the mammographic image (Warren et al 2013). The calcification HAp thicknesses $\left(t_{c}\right)$ ranged from 100 to $1000 \mu \mathrm{m}$, at $50 \mu \mathrm{m}$ increments. The corresponding thicknesses of calcite and calcium oxalate were calculated for all examined energies, in order the number of photons after attenuation $\left(I_{c, E_{i}}\right)$ to be equal. Then, the thicknesses for all energies were averaged for calcite and calcium oxalate, resulting in standard deviation (SD) lower than $20.87 \mu \mathrm{m}$. The HAp thicknesses and the corresponding thicknesses for $\mathrm{CaCO}_{3}$ and $\mathrm{CaC}_{2} \mathrm{O}_{4}$ are presented in table 1. The total breast thickness (T) was $4.2 \mathrm{~cm}$ (ACR 2006).

Table 1. Examined calcification thicknesses of $\mathrm{HAp}, \mathrm{CaCO}_{3}$ and $\mathrm{CaC}_{2} \mathrm{O}_{4}$.

\begin{tabular}{cccccc}
\hline \multicolumn{5}{c}{ Calcification thicknesses, tc $(\boldsymbol{\mu m})$} \\
\hline Hap & $\mathbf{C a C O}_{\mathbf{3}}$ & $\mathbf{C a C}_{\mathbf{2}} \mathbf{O}_{\mathbf{4}}$ & $\mathbf{H A p}$ & $\mathbf{C a C O}$ & $\mathbf{C a C}_{\mathbf{2}} \mathbf{O}_{\mathbf{4}}$ \\
\hline 100 & 123.72 & 208.49 & 600 & 742.30 & 1250.97 \\
150 & 185.57 & 312.74 & 650 & 804.15 & 1355.21 \\
200 & 247.29 & 416.99 & 700 & 866.01 & 1459.46 \\
250 & 309.29 & 521.24 & 750 & 927.87 & 1563.71 \\
300 & 371.15 & 625.48 & 800 & 989.73 & 1667.95 \\
350 & 433.01 & 729.73 & 850 & 1051.58 & 1772.20 \\
400 & 494.86 & 833.98 & 900 & 1113.44 & 1876.45 \\
450 & 556.72 & 938.22 & 950 & 1175.30 & 1980.69 \\
\hline
\end{tabular}




$\begin{array}{llllll}500 & 618.58 & 1040.47 & 1000 & 1237.16 & 2084.94\end{array}$

$550 \quad 680.44 \quad 1146.72$

The $\mathrm{m}_{\mathrm{Ca}} / \mathrm{m}_{\mathrm{P}}$ was then calculated for each calcification type, using Eq. A19 (please see Appendix). Note that hydroxyapatite indicated malignancy, whereas calcite and calcium oxalate are indicators of benign calcifications. When malignant calcifications are present, the model estimates the $\mathrm{m}_{\mathrm{Ca}} / \mathrm{m}_{\mathrm{P}}$ of hydroxyapatite where $\mathrm{Ca}$ and $\mathrm{P}$ are both elements in this molecule. On the contrary, $\mathrm{P}$ is not present in benign calcifications $\left(\mathrm{CaCO}_{3}, \mathrm{CaC}_{2} \mathrm{O}_{4}\right)$. In this case, the model calculates an effective $\mathrm{m}_{\mathrm{Ca}} / \mathrm{m}_{\mathrm{P}}$. In this method, where an unknown calcification type must be characterized by attenuation intensity measurements, the calculation of $\mathrm{m}_{\mathrm{Ca}} / \mathrm{m}_{\mathrm{P}}$ uses the linear attenuation coefficients of $\mathrm{PO}_{4}$ for all calcification types. The notation of 'effective' $\mathrm{m}_{\mathrm{Ca}} / \mathrm{m}_{\mathrm{P}}$ was introduced, since an amount of $\mathrm{CO}_{3}$ or $\mathrm{C}_{2} \mathrm{O}_{4}$ corresponds to a smaller amount of $\mathrm{PO}_{4}$, in order to preserve equal photon beam attenuation. This is due to the lower linear attenuation coefficients of carbonate and oxalate compared to phosphate. Thus, $\mathrm{m}_{\mathrm{Ca}} / \mathrm{m}_{\mathrm{P}}$ as calculated by Eq. A19 (please see Appendix) is expected to be lower for mineral types without phosphorus present in their molecule.

The coefficient of variation of the $\mathrm{m}_{\mathrm{Ca}} / \mathrm{m}_{\mathrm{P}}\left(\mathrm{CV}_{m_{C a} / m_{P}}(\%)\right)$ was calculated using Eq. A20 (please see Appendix) for each calcification type. The selection of the optimum energy pair was based on the minimization of the $C V_{m_{C a} / m_{P}}(\%)$. The $C V_{m_{C a} / m_{P}}(\%)$ of each mineral is referred to as $C V_{m_{C a} / m_{P}, H A p}(\%), C V_{m_{C a} / m_{P}, C a C O_{3}}(\%)$ and $C V_{m_{C a} / m_{P}, C a C_{2} O_{4}}(\%)$ for $\mathrm{HAp}, \mathrm{CaCO}_{3}$ and $\mathrm{CaC}_{2} \mathrm{O}_{4}$, respectively.

\subsubsection{Polyenergetic $X$-rays}

In order to obtain spectra with mean energies similar to those employed in the monoenergetic study, two different configurations were evaluated: (i) irradiation with the single exposure technique, and (ii) irradiation with the double exposure technique. For the implementation of the method using polyenergetic spectra, the linear attenuation coefficients were replaced by effective linear attenuation coefficients in Eqs. 1 and 2.

Unfiltered spectra were obtained from TASMIP spectral models generated for Tungsten (W) anode (Boone and Siebert 1997). The breast composition and thickness, as well as, the used calcification types and thicknesses were the same to those of the monoenergetic study.

\subsubsection{Single exposure}

In the single exposure technique, an appropriate filter was placed in the beam path (Sotiropoulou et al 2015, 2016). Filters with appropriate K-absorption edges were applied, in order to modify the X-ray spectrum in two well-separated energy bands with mean energies as indicated by the monoenergetic study (Koukou et al 2015, Martini et al 2015). Therefore, Rhodium (Rh), Palladium (Pd), Silver (Ag), Cadmium (Cd), Tin (Sn) and Iodine (I) filters with K-edges of $23.22 \mathrm{keV}, 24.35 \mathrm{keV}, 25.51 \mathrm{keV}, 26.71 \mathrm{keV}, 29.20 \mathrm{keV}$ and $33.17 \mathrm{keV}$, respectively, were applied at tube voltage of $70 \mathrm{kV}$. The filter thicknesses ranged from 100 to $1000 \mu \mathrm{m}$ at $50 \mu \mathrm{m}$ increments. The unfiltered spectrum was obtained for $300 \mathrm{mAs}$, corresponding to a 5 minutes measurement with a Norland XR-46 (Norland Medical Systems 
Inc., Fort Atkinson, WI) W anode X-ray source, operating at $70 \mathrm{kV}$ with a $1 \mathrm{~mA}$ current. An ionization chamber (Radcal 2026C) was positioned at a distance of $66 \mathrm{~cm}$ from the tube output and an entrance surface dose of 101.03 mGy was measured.

\subsubsection{Double exposure}

In the double exposure method, two separate images are acquired at two different $\mathrm{kVs}$ (Sorenson et al 1989). In order to obtain low-/high-energy spectra with mean energies similar to those indicated by the monoenergetic study, a radiographic unit with $\mathrm{W}$ anode is required. Commercially available radiographic units operate in the range from 40 to $150 \mathrm{kV}$, while mammographic units cannot be used since the tube does not exceed $50 \mathrm{kV}$. In a previous simulation study by our group, various filter materials and thicknesses, for the modification of the low-energy spectrum, were examined. Best results were obtained for the $100 \mu \mathrm{m} \mathrm{Cd}$ filtered spectrum at $40 \mathrm{kV}$, since this filter provided narrower spectra with adequate number of photons (Koukou et al 2015). For the modification of the high-energy spectrum, Copper $(\mathrm{Cu})$, Holmium (Ho), Thulium ( Tm) and Lutetium ( $\mathrm{Lu}$ ) filters were examined at $70 \mathrm{kV}$ for thicknesses in the range of 500 to $1500 \mu \mathrm{m}$ at $100 \mu \mathrm{m}$ increments. Copper is a commonly used low cost filter in X-ray systems since it attenuates the low energies in spectra. Ho, Tm and $\mathrm{Lu}$ are lanthanide filters with K-edges of $55.59 \mathrm{keV}, 59.37 \mathrm{keV}$ and $63.31 \mathrm{keV}$, respectively. The filters for the low-/high-energy were applied to unfiltered spectra obtained at 400 and $250 \mathrm{mAs}$, respectively. The $400 \mathrm{mAs}$ value for the low-energy was the maximum that could be obtained, while the $250 \mathrm{mAs}$ for the high-energy is a high value. An ionization chamber (Radcal 2026C) was positioned at $66 \mathrm{~cm}$ from the tube output and entrance surface doses of 11.32 and $28.90 \mathrm{mGy}$ were measured for the low- and high-energy, respectively.

\subsubsection{Nonparametric statistical analysis}

A statistical analysis was conducted using the polyenergetic X-rays. Assuming Poisson distribution for the attenuated intensities $\left(I_{b, E_{i}}\right.$ and $\left.I_{c, E_{i}}\right), 5000$ random values were generated for $I_{b, E_{i}}$ and $I_{c, E_{i}}$. Thus, $5000 \mathrm{~m} \mathrm{Ca} / \mathrm{m}_{\mathrm{P}}$ values were calculated using Eq. A19 (please see Appendix), for each calcification type $\left(\mathrm{HAp}, \mathrm{CaCO}_{3}, \mathrm{CaC}_{2} \mathrm{O}_{4}\right)$ and thickness. A statistical analysis was then followed to define the distribution that describes the random variable $\left(\mathrm{m}_{\mathrm{Ca}} / \mathrm{m}_{\mathrm{P}}\right)$ in each examined case. To this aim, nonparametric statistical methods were used, since the distribution of the random variable $\mathrm{m}_{\mathrm{Ca}} / \mathrm{m}_{\mathrm{P}}$ is unknown. The onesample Kolmogorov-Smirnov and chi-square tests were used with significance level set at 5\%. The normal Kernel distribution (Eq. 5) was applied to the data of the random variable $\mathrm{m}_{\mathrm{Ca}} / \mathrm{m}_{\mathrm{P}}$ as the p-value was higher than 0.05 in all cases.

$f(x)=\frac{1}{N h} \sum_{i=1}^{N} \frac{1}{\sqrt{2 \pi}} e^{-\frac{1}{2}\left(\frac{x-x_{i}}{h}\right)^{2}}, N=5000$

where $\mathrm{N}$ is the sample size, $\mathrm{x}_{\mathrm{i}}$ are the values of the random variable $\mathrm{m}_{\mathrm{Ca}} / \mathrm{m}_{\mathrm{P}}$, and $\mathrm{h}$ is the bandwidth. The bandwidth controls the smoothness of Kernel function, because it determines 
how the probability associated with each observation is spread over the surrounding sample (Bowman and Azzalini 1997). There are a number of techniques that automatically choose the bandwidth (Jones et al 1996). In the current study, the 'fitdist' routine of Matlab R2017a was used to obtain the Kernel distribution and the bandwidth.

The Kernel probability functions were produced for all calcification types and thicknesses. The probability distribution functions obtained from HAp were plotted together with the corresponding functions of $\mathrm{CaCO}_{3}$ and $\mathrm{CaC}_{2} \mathrm{O}_{4}$. The false negative and false positive values were calculated from the probability distribution functions.

The nonparametric statistical analysis was also conducted for breast thicknesses of 5 and 6 $\mathrm{cm}$, in order to investigate the influence of breast thickness on the false negative and false positive values.

\subsection{Experimental evaluation of the method 2.2.1. Calcification phantoms}

For the evaluation of the method, twelve different calcification phantoms were constructed: four HAp thicknesses and the corresponding thicknesses of calcite and calcium oxalate (4 thicknesses $\times 3$ minerals $=12$ phantoms). The HAp thicknesses were 300, 500, 700, $900 \mu \mathrm{m}$ and the corresponding thicknesses of calcite and calcium oxalate are shown in table 1 . The materials used in this study, were hydroxyapatite (FLUKA $21223, \geq 90 \%$ purity), calcium carbonate (CAS Nr: 207-439-9, $\geq$ 99\% purity), calcium oxalate (CAS Nr: 563-72-4, 99.99\% purity) and deionized water. Polymethyl methacrylate (PMMA) tubes, with an outer diameter of $2 \mathrm{~cm}$ and length of $3 \mathrm{~cm}$, were filled with a mixture of the aforementioned materials and double distilled water (figure 2). The cylinder phantoms were sealed in both top and bottom with $0.5 \mathrm{~mm}$ PMMA discs. A vacuum tube was used to diminish the remaining air in the phantoms. Each phantom was immersed in a cubic PMMA tank $\left(10 \times 10 \times 10 \mathrm{~cm}^{3}\right)$, filled with water $(4.2 \mathrm{~cm}$ thickness), simulating the average breast. Two PMMA discs, with equal dimensions as those used for the sealed cylinder phantoms, were placed in the beam path when measurements without the cylinder phantoms were performed.
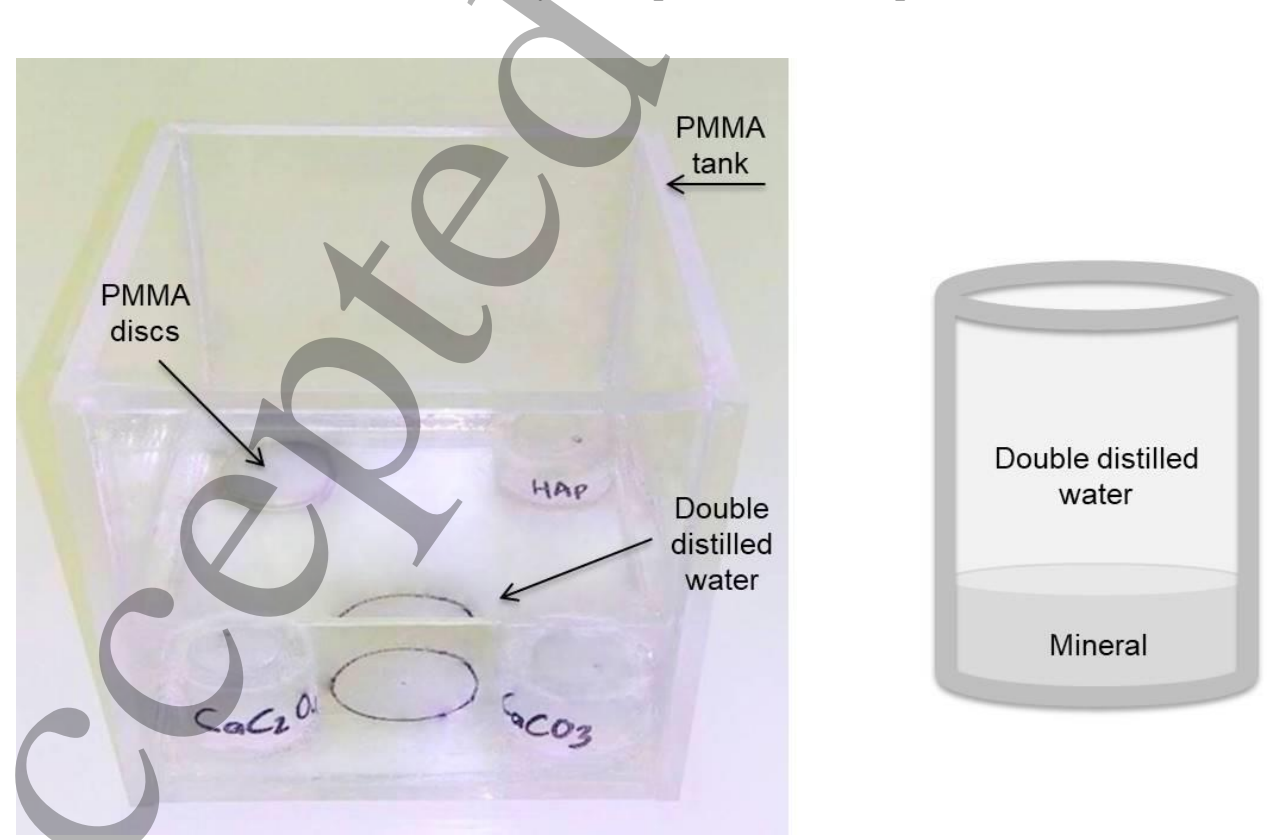

Figure 2. Photo of the tank with the immersed calcification phantoms (left) and schematic representation of the phantom (right). 


\subsubsection{Single exposure technique}

The X-ray source was a tungsten (W) anode Norland XR-46 (Norland Medical Systems Inc., Fort Atkinson, WI) operating at 60 to $100 \mathrm{kV}$ and 0.05 to $1 \mathrm{~mA}$ current. Appropriate collimation ( $1 \mathrm{~mm}$ radius) was applied, in order to obtain a narrow pencil beam, resulting in limited scatter contribution to the spectra. The inherent Samarium filter employed by Norland was extracted and replaced by $300 \mu \mathrm{mCd}$, as indicated by the simulation study. A tube current of $0.5 \mathrm{~mA}$ was used in the measurements. A Cadmium Telluride (CdTe) X-ray energy discriminating and counting system (AMPTEK XR-100T) was used (Michail et al 2011a, 2011b). The digital processor was the PX4. The energy calibration of the detection system was performed using ${ }^{125} \mathrm{I}$ and ${ }^{99 \mathrm{~m}} \mathrm{Tc} \gamma$-ray calibration sources (Martini et al 2015). The measured X-ray spectra were corrected for both the CdTe detector efficiency and the dead time of the digital processor (Sotiropoulou et al 2015). The selected low-energy band consisted of energies in the range of 23.04 to $26.99 \mathrm{keV}$, while the high-energy band was in the range of 50.10 to $64.06 \mathrm{keV}$. Two sequential measurements were obtained using the constructed phantoms, the first with only the water in the radiation path, and the second with the calcification phantom along the radiation path and immersed in the water tank. In both measurements, the total thickness was kept constant and equal to $4.2 \mathrm{~cm}$. The acquisition time was 5 minutes. Ten repeated measurements were obtained in order to determine the $\mathrm{m}_{\mathrm{Ca}} / \mathrm{m}_{\mathrm{P}}$ and the coefficient of variation of the measurements ( $C V_{m_{C a} / m_{P}, \text { meas }}(\%)=S D_{m_{C a} / m_{P}} /$ mean $\left._{m_{C a} / m_{P}}\right)$. The experimental configuration is shown in figure 3.

\subsubsection{Double exposure technique}

The Del Medical Eureka W anode radiographic system was used with added filtration of 100 $\mu \mathrm{m}$ Cd (Alfa Aesar 11371, 99.9975\%) at $40 \mathrm{kV}, 400 \mathrm{mAs}$ and $1000 \mu \mathrm{m}$ Cu (PTW 99.99\%) at $70 \mathrm{kV}, 250 \mathrm{mAs}$ for the low- and high-energy spectra, respectively (Koukou et al 2017a). The detection system was a terbium-doped gadolinium oxysulfide $\left(\mathrm{Gd}_{2} \mathrm{O}_{2} \mathrm{~S}\right.$ :Tb) phosphor screen (Min-R 2190 with mass thickness of $33.91 \mathrm{mg} / \mathrm{cm}^{2}$ ) coupled to an optical readout device including a complementary metal-oxide-semiconductor (CMOS) Remote RadEye HR photodiode pixel array. The CMOS photodiode array has a format of $1200 \times 1600$ pixels, corresponding to an active area of $27 \mathrm{~mm} \times 36 \mathrm{~mm}$, with a pixel pitch of $22.5 \mu \mathrm{m}$. The $\mathrm{Gd}_{2} \mathrm{O}_{2} \mathrm{~S}$ : Tb screen was directly overlaid onto the active area of the CMOS (no fiber optic plate or coupling gel were used) (Michail et al 2011b). The source-to-detector distance (SDD) was set at $66 \mathrm{~cm}$.

Since for the determination of $\mathrm{m}_{\mathrm{Ca}} / \mathrm{m}_{\mathrm{P}}$ the total number of photons (i.e. $I_{b, E_{i}}, I_{c, E_{i}}$ ) is required, the pixel values of the low- and high-energy images should be converted to photons. The detector response curve was measured in order to convert pixel values to dose and in turn, with known $I_{b, E_{i}}, I_{c, E_{i}}$ spectra, to photons using Eq. 3 rewritten as follows (Koukou et al 2015): 


$$
K_{a}(m G y)=8.77 * 10^{-3} \sum_{E_{\min }}^{E_{\max }} 1.83 * 10^{-6} I_{E_{i}} E_{i}\left(\frac{\mu_{e n}}{\rho_{E_{i}}}\right)_{\text {air }}
$$

A PMMA tank filled with water of $4.2 \mathrm{~cm}$ total thickness, was positioned at $61.8 \mathrm{~cm}$ (source to object distance, SOD) from the tube exit and exposed using tube voltages of 40 and $70 \mathrm{kV}$ for the low- and high-energy, respectively (Koukou et al 2015). The SDD was $66 \mathrm{~cm}$. The experimental configuration is shown in figure 3. An ionization chamber (Radcal 2026C) was positioned at the surface of the breast phantom. The entrance surface air kerma was measured for a range of tube current-time products. Both LE and HE images were saved as 16 bit and 100x100 pixels square regions of interest (ROIs) were measured from each image. The mean pixel value (MPV) and the standard deviation within that region were measured and the relationship between MPV and the detector entrance dose was determined using linear regression (figure 4).

\section{Single Exposure}

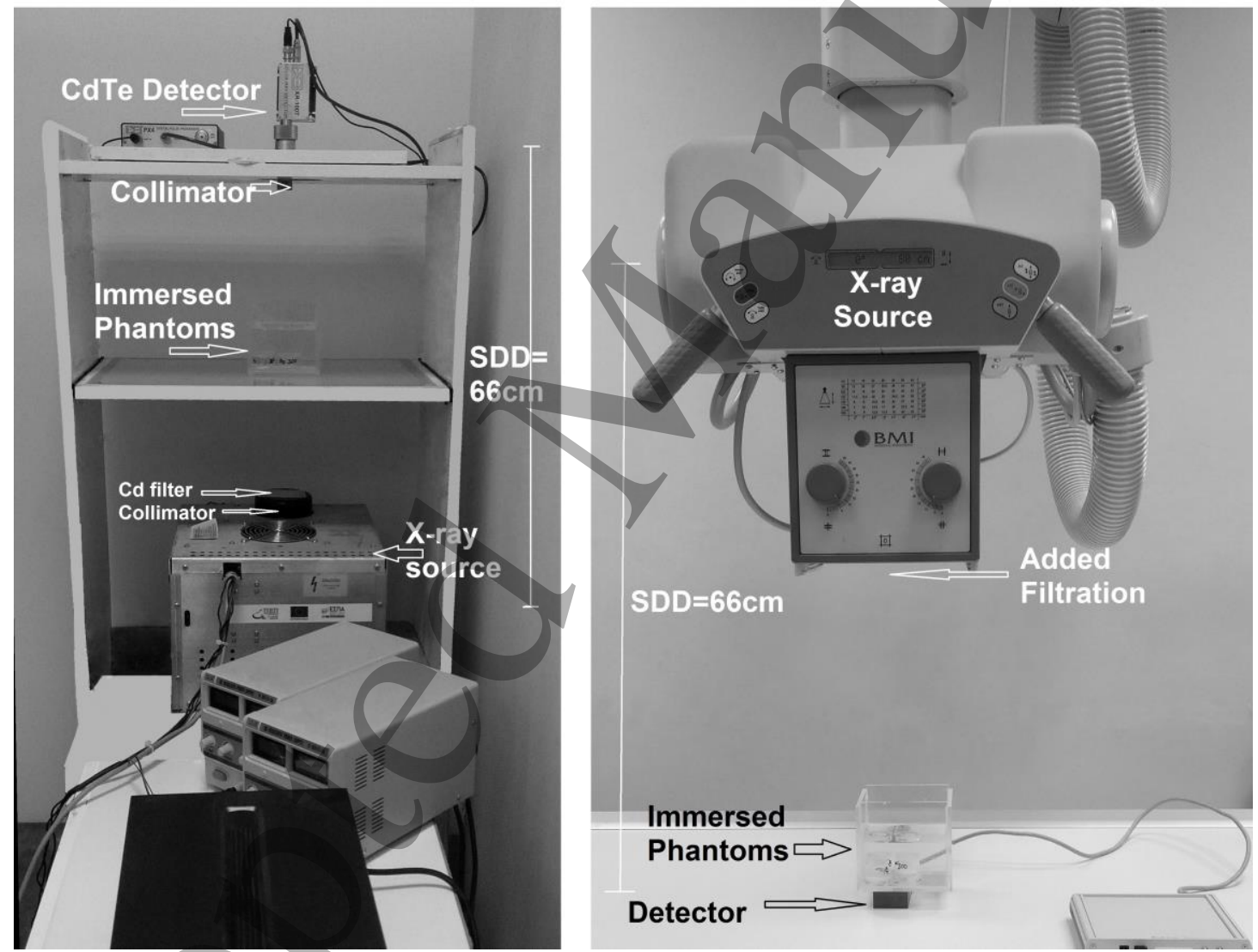

Figure 3. Experimental configuration for single and double exposure techniques. 

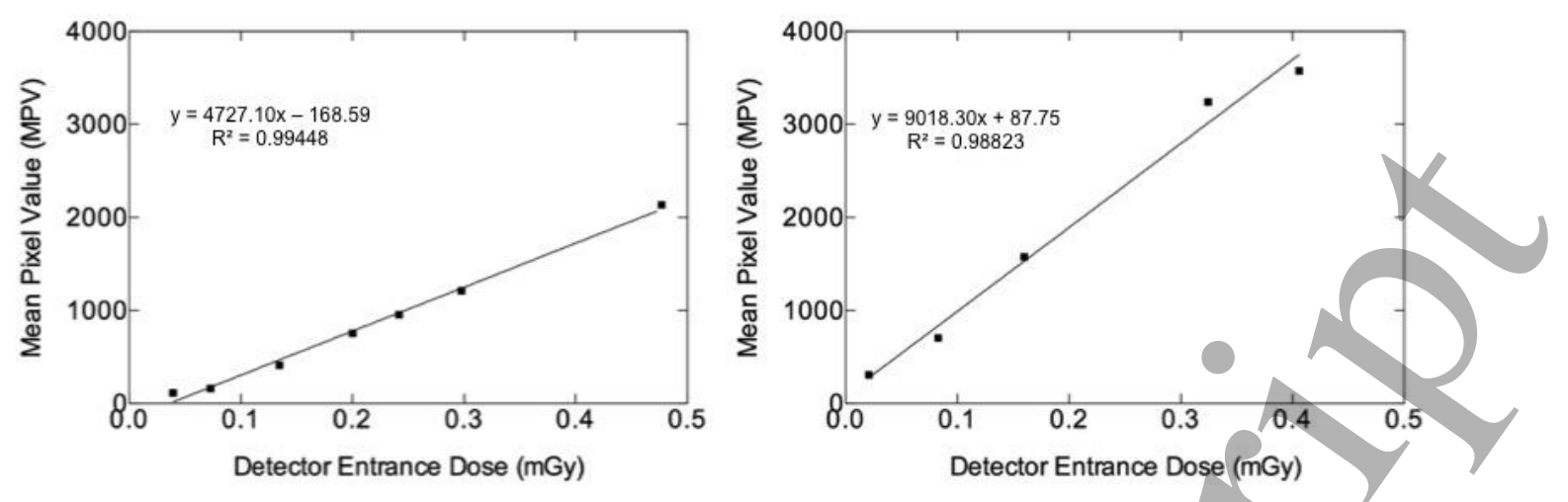

Figure 4. MPV as a function of the detector entrance dose for the low (left)-and high-energy (right).

Five low and five high-energy images were acquired for each calcification phantom in order to determine the $\mathrm{m}_{\mathrm{Ca}} / \mathrm{m}_{\mathrm{P}}$ and the coefficient of variation ( $C V_{m_{C a} / m_{P}, \text { meas }}(\%)=S D_{m_{C a} / m_{P}} /$ mean $\left._{m_{C a} / m_{P}}\right)$. Between acquisitions, of each pair of low and high-energy images, the phantoms were repositioned. The phantom images were acquired with the irradiation conditions mentioned above and saved as 16 bit. Twenty ROIs of $44 \times 44$ pixels were selected in each image and the MPVs were converted into photons for the estimation of the $\mathrm{m}_{\mathrm{Ca}} / \mathrm{m}_{\mathrm{P}}$. In order to convert the MPV into number of photons, the measured $100 \mu \mathrm{m} \mathrm{Cd}$ and $1000 \mu \mathrm{m} \mathrm{Cu}$ filtered spectra, by the AMPTEK CdTe spectrometer, were used for the low- and high-energy, respectively (figure 5). The detector system was calibrated for energy scales, linearity checks and energy resolution, by using ${ }^{125} \mathrm{I}$ and ${ }^{99 \mathrm{~m}} \mathrm{Tc} \gamma$-ray calibration sources (Martini et al 2015).

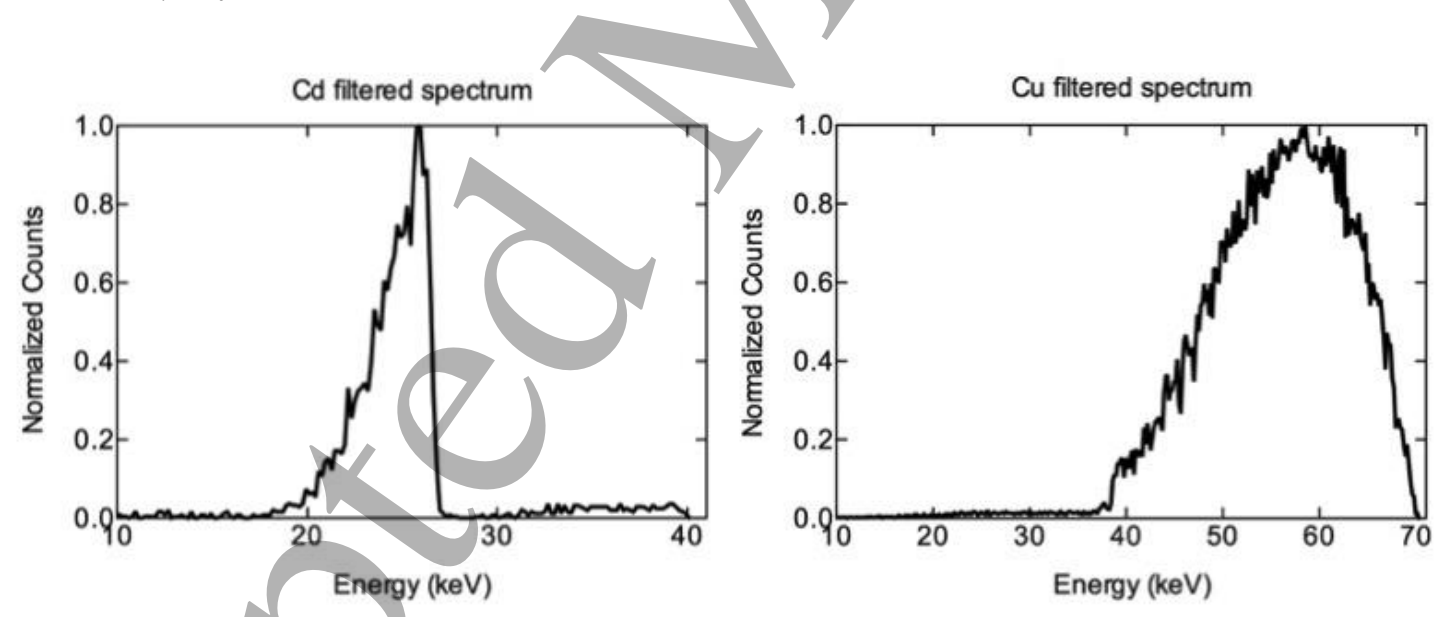

Figure 5. The $100 \mu \mathrm{m} \mathrm{Cd}$ and $1000 \mu \mathrm{m} \mathrm{Cu}$ filtered spectra for the low- and high-energy, respectively.

\subsubsection{Statistical analysis}

Since $\mathrm{m}_{\mathrm{Ca}} / \mathrm{m}_{\mathrm{P}}$ probability distribution is not Gaussian, the Mann-Whitney $\mathrm{U}$ nonparametric statistical test was applied to the measured $m_{C a} / m_{P}$ values, in order to assess statistical significant difference between the different types of the examined minerals (Milton 1964). The Mann-Whitney $U$ test is similar to t-test for the determination of statistical separation of two populations; however, it does not assume any specific distribution of the 
data, unlike the t-test where a normal distribution is prerequisite (Milton 1964). All tests were two-tailed and the significance level was set at $5 \%$.

\section{Results}

\subsection{Simulation studies \\ 3.1.1.Monoenergetic beams}

Figure 6 shows the $C V_{m_{C a} / m_{P}}(\%)$ of each mineral type and thickness as a function of lowand high-energy combinations. In this figure the $C V_{m_{C a} / m_{P}}(\%)$ values ranged from the minimum $C V_{m_{C a} / m_{P}}(\%)$ value, obtained in each case, up to $+50 \%$ of the minimum $C V_{m_{C a} / m_{P}}(\%)$, as calculated by Eq. A19. The 'fit' routine of Matlab R2017a was used for the presented surface plot. The indicative thicknesses presented are 100,500 and $1000 \mu \mathrm{m}$ of HAp and the corresponding thicknesses of $\mathrm{CaCO}_{3}$ and $\mathrm{CaC}_{2} \mathrm{O}_{4}$ shown in table 1 . In this study, the selected energy combinations were those resulting in $20 \%$ (or less) of the minimum $C V_{m_{C a} / m_{P}}(\%)$. This criterion is fulfilled for every energy combination that can be obtained when the low-energy ranges from 23 to $27 \mathrm{keV}$ and the high-energy ranges from 53 to 70 $\mathrm{keV}$, for all minerals.
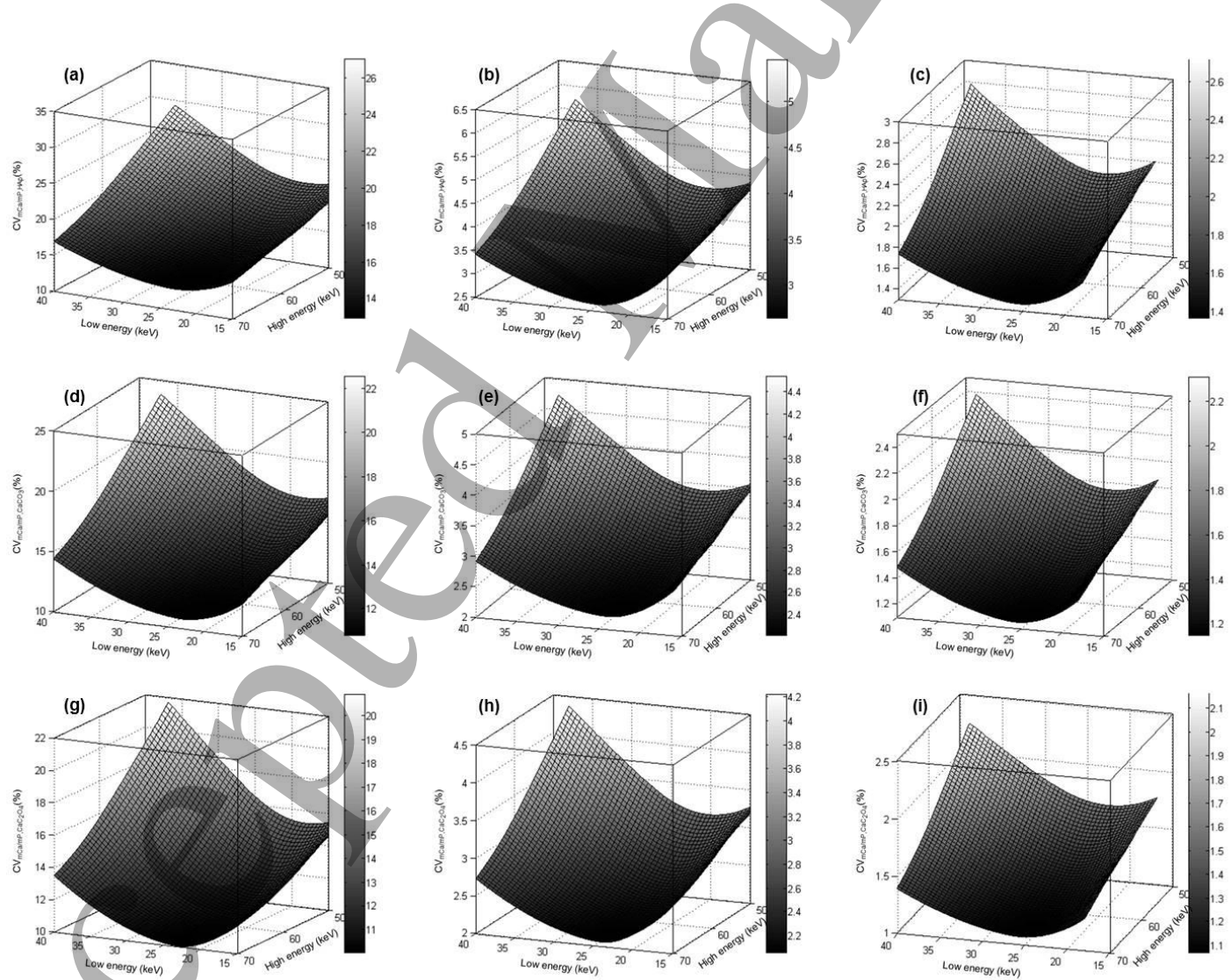

Figure 6. $C V_{m_{C a} / m_{P}, H A p}(\%)$ (first row), $C V_{m_{C a} / m_{P}, C a C O_{3}}(\%)$ (second row), and $C V_{m_{C a} / m_{P}, \mathrm{CaC}_{2} \mathrm{O}_{4}}(\%)$ (third row) as a function of low- and high-energy for $100 \mu \mathrm{m}$ (a,d,g), $500 \mu \mathrm{m}(\mathrm{b}, \mathrm{e}, \mathrm{h})$ and $1000 \mu \mathrm{m}(\mathrm{c}, \mathrm{f}, \mathrm{i})$ thicknesses. 


\subsubsection{Polyenergetic $X$-rays \\ 3.1.2.1. Single exposure}

Figure 7 shows the normalized spectra at $70 \mathrm{kV}$ modified with $\mathrm{Rh}, \mathrm{Pd}, \mathrm{Ag}, \mathrm{Cd}, \mathrm{Sn}$ and I filters with thicknesses from 100 to $1000 \mu \mathrm{m}$, at $100 \mu \mathrm{m}$ increments. These spectra were used as input data to the simulation of the current study, for the selection of filter material and thickness, as described below. Improved separation of the low- and high- energy bands can be achieved by all filter materials tested as the filter thickness increases. However, thicker filters lead to poor statistics due to the decreased number of photons.
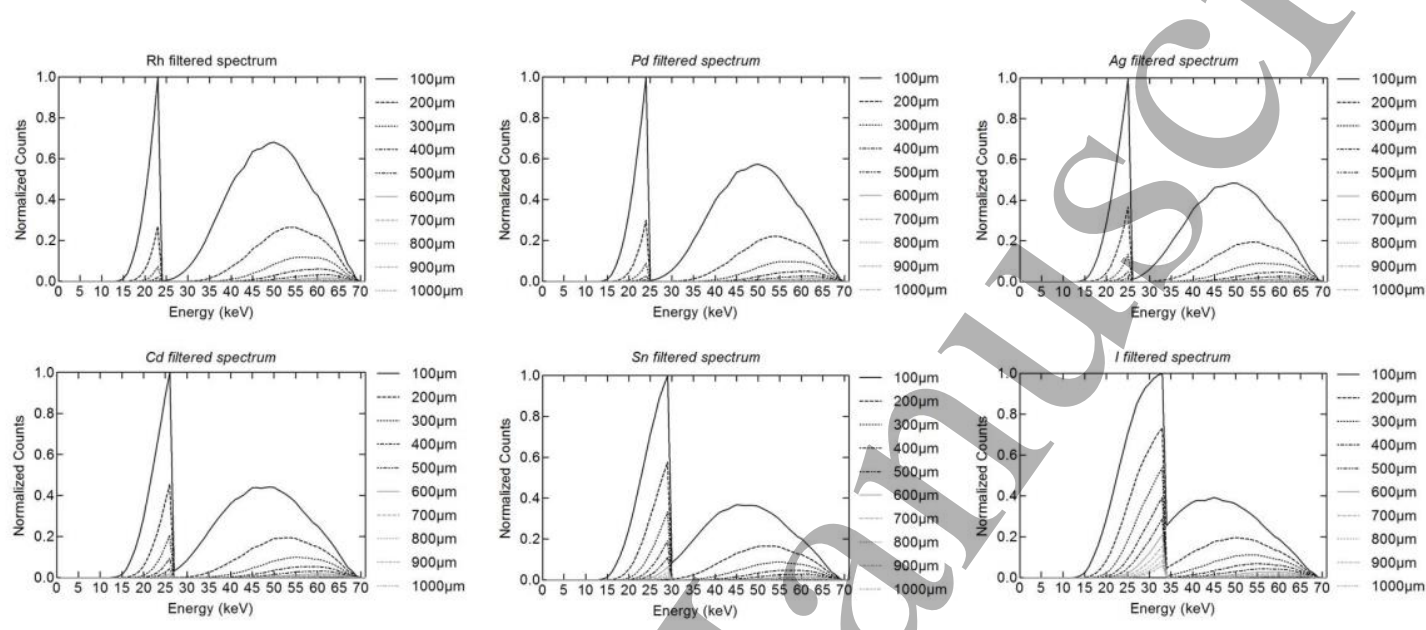

Figure 7. Filtered spectra with $\mathrm{Rh}, \mathrm{Pd}, \mathrm{Ag}, \mathrm{Cd}, \mathrm{Sn}$ and I with thicknesses from 100 to 1000 $\mu \mathrm{m}$, in $100 \mu \mathrm{m}$ increments, at $70 \mathrm{kV}$.

Figure 8 shows the mean energies for the low- and high-energy spectra filtered with $\mathrm{Rh}, \mathrm{Pd}$, $\mathrm{Ag}, \mathrm{Cd}, \mathrm{Sn}$ and $\mathrm{I}$ as a function of surface density $\left(\mathrm{g} / \mathrm{cm}^{2}\right)$. Over the whole surface density range, only $\mathrm{Ag}$ and $\mathrm{Cd}$ filters have mean energies in the range indicated by the monoenergetic study. The dotted lines correspond to 23 and $27 \mathrm{keV}$, the lower and the upper limit for the low-energy indicated by the monoenergetic study.

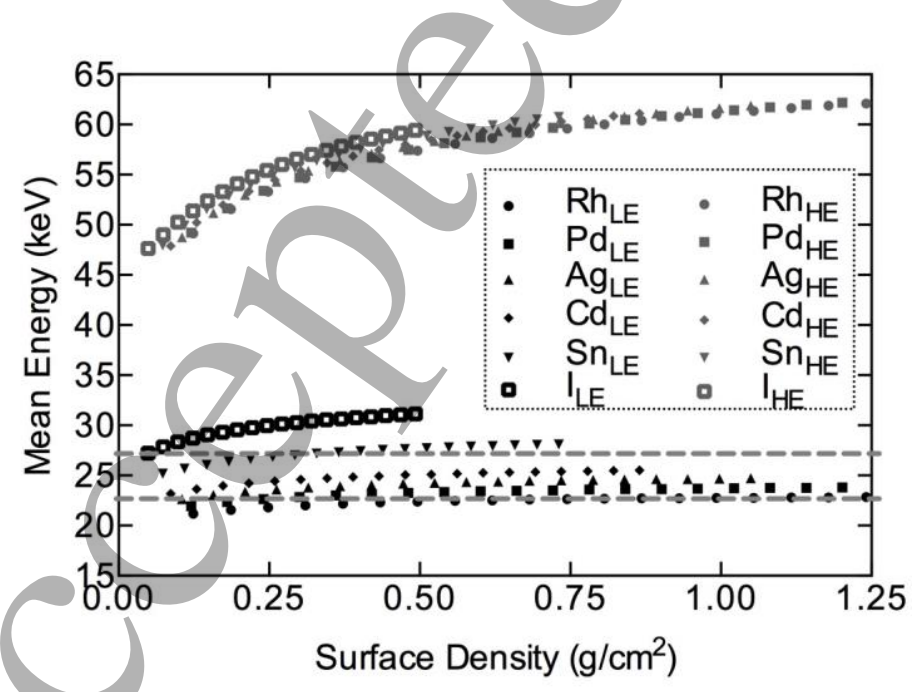

Figure 8. Low- and high-energy mean energies of $\mathrm{Rh}, \mathrm{Pd}, \mathrm{Ag}, \mathrm{Cd}$, Sn and I filtered spectra, as a function of filters' surface densities. 
The averaged difference in mean energies of $\mathrm{Ag}$ and $\mathrm{Cd}$ filtered spectra was less than 0.6 and $0.8 \mathrm{keV}$ for the low- and high-energy bands, respectively, across the examined surface density range. The $\mathrm{Cd}$ filter was selected, as it was available to our laboratory.

Figure 9 shows the $C V_{m_{C a} / m_{P}}(\%)$ of $500,618.58$ and $1040.47 \mu \mathrm{m} \mathrm{HAp}, \mathrm{CaCO}_{3}$ and $\mathrm{CaC}_{2} \mathrm{O}_{4}$, respectively, plotted as a function of examined $\mathrm{Cd}$ surface densities and entrance dose. For surface densities in the range of 0.22 to $0.39 \mathrm{~g} / \mathrm{cm}^{2}$, the entrance doses are lower than the mammography acceptable levels $(6 \mathrm{mGy})$, as shown by the dotted line (European Commission 2014), with relatively low $C V_{m_{C a} / m_{P}}(\%)$ values (<7\%). The Cd surface density that was selected for this study is $0.26 \mathrm{~g} / \mathrm{cm}^{2}$, corresponding to a thickness of $300 \mu \mathrm{m}$. At this thickness, there is a compromise between low $C V_{m_{C a} / m_{P}}(\%)$ and dose (3.29 mGy) values for all calcification types. The low- and high-mean energies are $24 \mathrm{keV}$ and $55 \mathrm{keV}$, respectively.

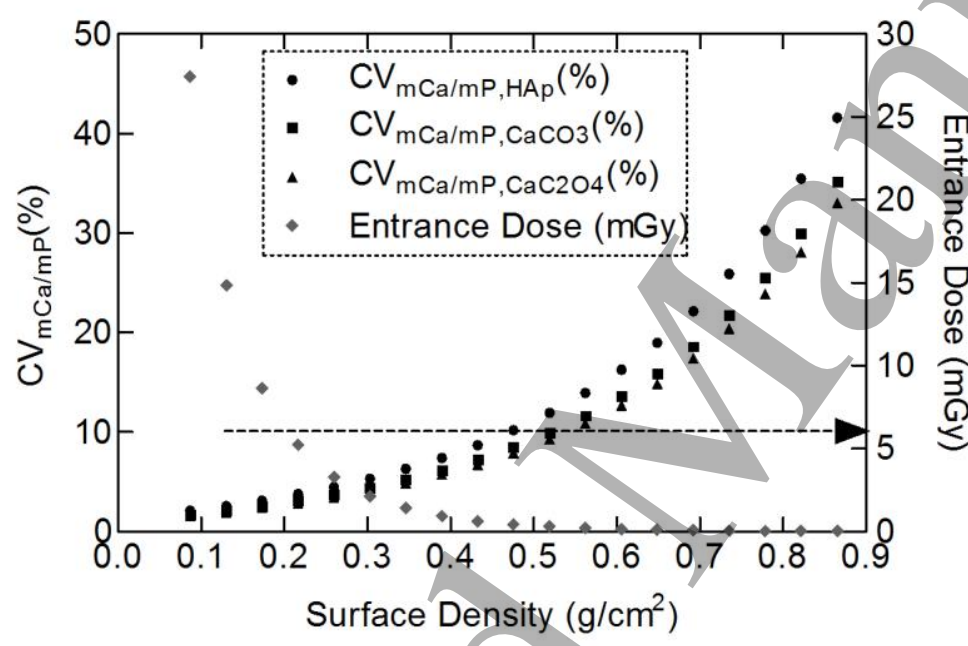

Figure 9. $C V_{m_{\mathrm{Ca}} / m_{P}, \mathrm{HAp}}(\%), C V_{m_{\mathrm{Ca}} / m_{P}, \mathrm{CaCO}_{3}}(\%)$ and $\mathrm{CV}_{m_{\mathrm{Ca}} / m_{P}, \mathrm{CaC}_{2} \mathrm{O}_{4}}(\%)$ as a function of entrance dose and the examined $\mathrm{Cd}$ surface densities.

Figure 10 shows indicative probability distribution functions for $100 \mu \mathrm{m}$ HAp, $123.72 \mu \mathrm{m}$ $\mathrm{CaCO}_{3}$ and $208.49 \mu \mathrm{m} \mathrm{CaC}_{2} \mathrm{O}_{4}$. The HAp probability distribution function is plotted together with $\mathrm{CaCO}_{3}$ (left) and $\mathrm{CaC}_{2} \mathrm{O}_{4}$ (right) probability distribution functions. The grey dashed lines indicate the intersection point of the probability distribution functions, separating the overlap area into the false negative (FN) and false positive (FP). 

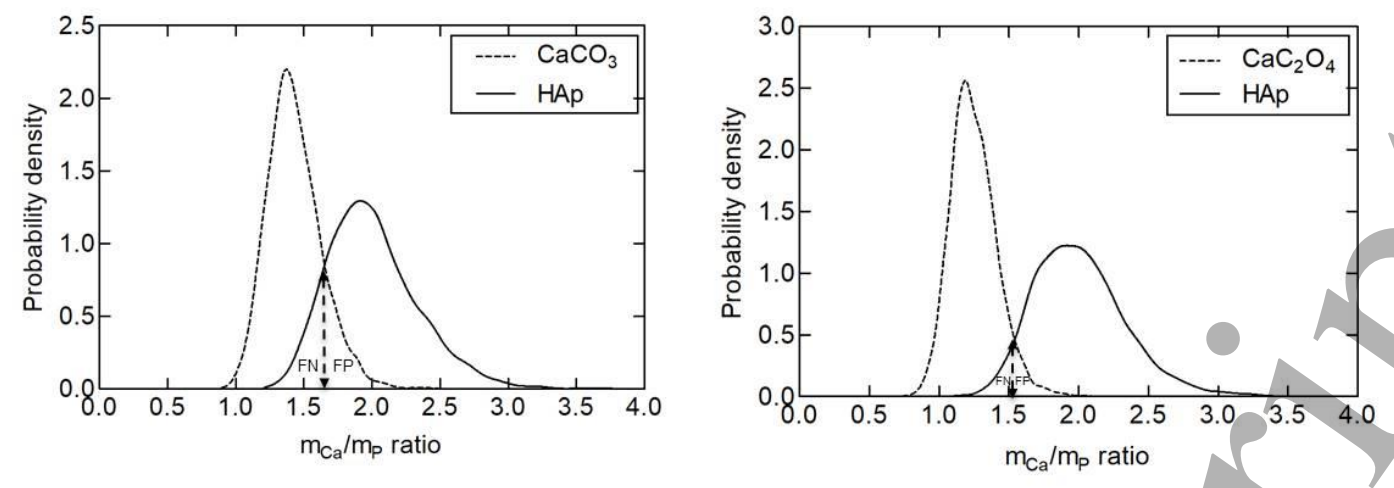

Figure 10. Indicative probability distribution functions for $100 \mu \mathrm{m}$ HAp, $123.72 \mu \mathrm{m} \mathrm{CaCO}_{3}$ and $208.49 \mu \mathrm{m} \mathrm{CaC}_{2} \mathrm{O}_{4}$.

Table 2 shows the false negative (\%) and false positive (\%) values, as well as the overlap area $(\%)$, defined as the sum of these values, for the single exposure technique. The results presented here are for calcification thicknesses of 100, 300, 500, 700 and $900 \mu \mathrm{m} \mathrm{HAp}$ and the corresponding thicknesses for $\mathrm{CaCO}_{3}$ and $\mathrm{CaC}_{2} \mathrm{O}_{4}$ and breast thicknesses of 4.2, 5 and 6 $\mathrm{cm}$. For all breast thicknesses, the entrance dose was kept at $3.29 \mathrm{mGy}$. The $C V_{m_{C a} / m_{P}, H A p}(\%)$ for all examined calcification thicknesses ranged from: (i) 2.37 to $21.67 \%$ for $4.2 \mathrm{~cm}$, (ii) 2.63 to $23.81 \%$ for $5 \mathrm{~cm}$, and (iii) 3.02 to $26.92 \%$ for $6 \mathrm{~cm}$. The $\mathrm{CV}_{\mathrm{m}_{\mathrm{Ca}} / m_{P}, \mathrm{CaCO}_{3}}(\%)$ for all examined calcification thicknesses ranged from: (i) 1.95 to $17.83 \%$ for $4.2 \mathrm{~cm}$, (ii) 2.17 to $19.60 \%$ for $5 \mathrm{~cm}$, and (iii) 2.50 to $22.19 \%$ for $6 \mathrm{~cm}$. The $\mathrm{CV}_{\mathrm{m}_{\mathrm{Ca}} / \mathrm{m}_{\mathrm{P}}, \mathrm{CaC}_{2} \mathrm{O}_{4}}(\%)$ for all examined calcification thicknesses ranged from: (i) 1.82 to $16.63 \%$ for $4.2 \mathrm{~cm}$, (ii) 2.02 to $18.30 \%$ for $5 \mathrm{~cm}$, and (iii) 2.32 to $20.73 \%$ for $6 \mathrm{~cm}$.

Table 2. Overlap area-OA (\%), false negative-FN (\%) and false positive-FP (\%) values for indicative thicknesses for the single exposure technique.

\begin{tabular}{|c|c|c|c|c|c|c|c|c|c|c|}
\hline \multirow[b]{2}{*}{ Case } & \multirow[b]{2}{*}{$\begin{array}{c}\mathbf{t}_{\mathrm{HAp}} \\
(\boldsymbol{\mu m})\end{array}$} & \multicolumn{3}{|c|}{$T=4.2 \mathrm{~cm}$} & \multicolumn{3}{|c|}{$T=5 \mathrm{~cm}$} & \multicolumn{3}{|c|}{$T=6 \mathrm{~cm}$} \\
\hline & & $\begin{array}{l}\text { OA } \\
(\%)\end{array}$ & $\begin{array}{l}\text { FN } \\
(\%)\end{array}$ & $\begin{array}{l}\mathbf{F P} \\
(\%)\end{array}$ & $\begin{array}{l}\text { OA } \\
(\%)\end{array}$ & $\begin{array}{l}\text { FN } \\
(\%)\end{array}$ & $\begin{array}{c}\text { FP } \\
(\%)\end{array}$ & $\begin{array}{l}\mathbf{O A} \\
(\%)\end{array}$ & $\begin{array}{c}\text { FN } \\
(\%)\end{array}$ & $\begin{array}{c}\mathbf{F P} \\
(\%)\end{array}$ \\
\hline \multirow{5}{*}{$\begin{array}{l}\text { HAp; } \\
\mathrm{CaCO}_{3}\end{array}$} & 100 & 79.82 & 40.94 & 38.88 & 82.90 & 43.40 & 39.50 & 98.99 & 2.89 & 96.10 \\
\hline & 300 & 14.96 & 7.63 & 7.33 & 18.92 & 9.88 & 9.04 & 25.26 & 12.93 & 12.33 \\
\hline & 500 & 1.82 & 0.92 & 0.90 & 3.29 & 1.65 & 1.64 & 6.29 & 3.19 & 3.10 \\
\hline & 700 & .08 & 0.04 & 0.04 & 0.34 & 0.16 & 0.18 & 0.97 & 0.48 & 0.49 \\
\hline & 900 & 0.00 & 0.00 & 0.00 & 0.01 & 0.01 & 0.00 & 0.08 & 0.04 & 0.04 \\
\hline \multirow{5}{*}{$\begin{array}{c}\text { HAp; } \\
\mathrm{CaC}_{2} \mathrm{O}_{4}\end{array}$} & 100 & 68.46 & 14.48 & 53.98 & 80.73 & 10.33 & 70.40 & 95.45 & 5.02 & 90.43 \\
\hline & 300 & & 1.56 & 1.62 & 5.27 & 2.73 & 2.54 & 8.77 & 4.43 & 4.34 \\
\hline & 500 & 0.03 & 0.03 & 0.00 & 0.09 & 0.06 & 0.03 & 0.44 & 0.23 & 0.21 \\
\hline & 700 & 0.00 & 0.00 & 0.00 & 0.00 & 0.00 & 0.00 & 0.00 & 0.00 & 0.00 \\
\hline & 900 & 0.00 & 0.00 & 0.00 & 0.00 & 0.00 & 0.00 & 0.00 & 0.00 & 0.00 \\
\hline
\end{tabular}

3.1.2.2. Double exposure

Figure 11 shows $C V_{m_{C a} / m_{P}, H A p}(\%), C V_{m_{C a} / m_{P}, C_{C C O}}(\%)$ and $C V_{m_{C a} / m_{P}, C a C_{2} O_{4}}(\%)$ for 
$500 \mu \mathrm{m}$ HAp and the corresponding thicknesses for $\mathrm{CaCO}_{3}$ and $\mathrm{CaC}_{2} \mathrm{O}_{4}$, as a function of surface density $\left(\mathrm{g} / \mathrm{cm}^{2}\right)$ for all the high-energy filters $(\mathrm{Cu}, \mathrm{Ho}, \mathrm{Tm}$, and $\mathrm{Lu})$, combined with a $\mathrm{Cd}$ filter of $100 \mu \mathrm{m}$ thickness for the low-energy. Copper was selected as the high-energy filter due to its lower $C V_{m_{C a} / m_{P}}(\%)$ values compared to the other filters, for all calcification types.

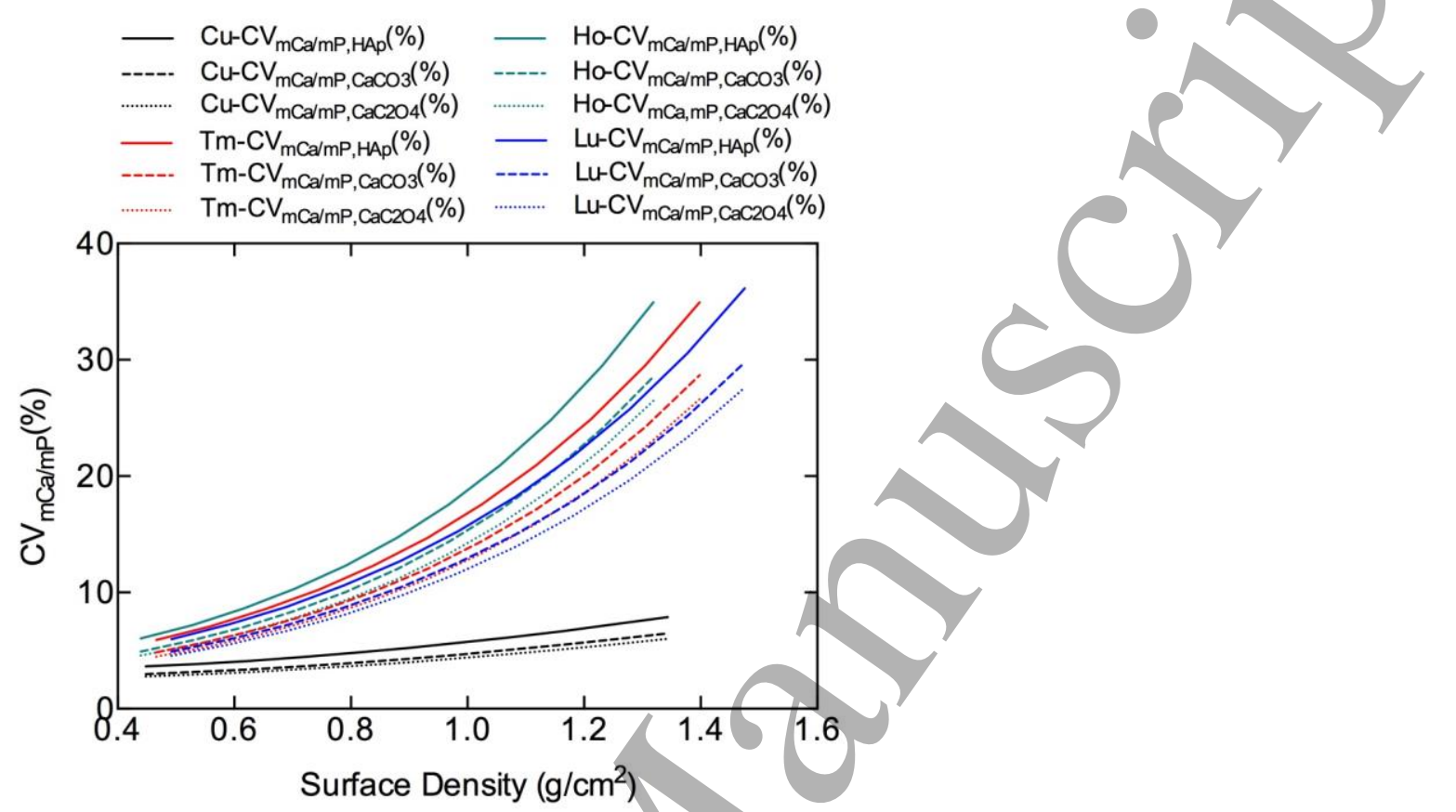

Figure 11. $C V_{m_{C a} / m_{P}, H A p}(\%), C V_{m_{C a} / m_{P}, C a C O}(\%)$ and $C V_{m_{C a} / m_{P}, C a C_{2} O_{4}}(\%)$ as a function of surface density for all high-energy filters with $100 \mu \mathrm{m} \mathrm{Cd}$ (low-energy filter).

Figure 12 shows $C V_{m_{C a} / m_{P}, H A p}(\%), C V_{m_{C a} / m_{P}, C_{C a C O}}(\%), C V_{m_{C a} / m_{P}, C a C_{2} O_{4}}(\%)$ and entrance dose as a function of surface density $\left(\mathrm{g} / \mathrm{cm}^{2}\right)$ of $\mathrm{Cu}$ combined with a $\mathrm{Cd}$ filter of 100 $\mathrm{m}$ thickness. The $C V_{m_{C a} / m_{P}}(\%)$ data correspond to $500,618.58$ and $1040.47 \mu \mathrm{m} \mathrm{HAp}$, $\mathrm{CaCO}_{3}$ and $\mathrm{CaC}_{2} \mathrm{O}_{4}$, respectively. For the whole surface density range, the entrance surface dose was within the acceptable levels (6 mGy). In order the entrance dose to be comparable with the single exposure method, $0.89 \mathrm{~g} / \mathrm{cm}^{2}$ surface density was selected, since it results in total entrance dose of $3.25 \mathrm{mGy}$. 


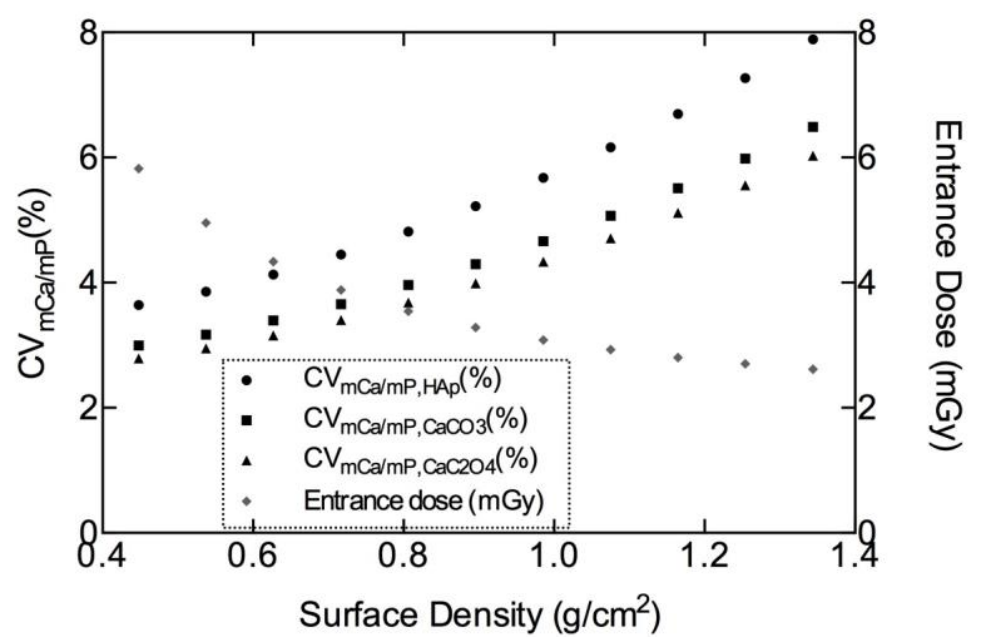

Figure 12. $C V_{m_{C a} / m_{P}, H A p}(\%), C V_{m_{C a} / m_{P}, C_{C O C O}}(\%)$ and $C V_{m_{C a} / m_{P}, C a C_{2} O_{4}}(\%)$ as a function of surface density $\left(\mathrm{g} / \mathrm{cm}^{2}\right)$ of $\mathrm{Cu}$ combined with a Cd filter of $100 \mu \mathrm{m}$ thickness and entrance dose.

Table 3 shows the false negative (\%), false positive (\%) and overlap area (\%) values for calcification thicknesses of 100,300, 500, 700 and $900 \mu \mathrm{m} \mathrm{HAp}$ and the corresponding thicknesses for $\mathrm{CaCO}_{3}$ and $\mathrm{CaC}_{2} \mathrm{O}_{4}$ and breast thicknesses of $4.2,5$ and $6 \mathrm{~cm}$. The $C V_{m_{C a} / m_{P}, H A p}(\%)$ for all examined calcification thicknesses ranged from: (i) 2.71 to $25.51 \%$ for $4.2 \mathrm{~cm}$, (ii) 2.97 to $27.81 \%$ for $5 \mathrm{~cm}$, and (iii) 3.34 to $31.03 \%$ for $6 \mathrm{~cm}$. The $\mathrm{CV}_{m_{\mathrm{Ca}} / m_{P}, \mathrm{CaCO}_{3}}(\%)$ for all examined calcification thicknesses ranged from: (i) 2.23 to $20.93 \%$ for $4.2 \mathrm{~cm}$, (ii) 2.45 to $22.82 \%$ for $5 \mathrm{~cm}$, and (iii) 2.75 to $25.49 \%$ for $6 \mathrm{~cm}$. The $\mathrm{CV}_{m_{\mathrm{Ca}} / \mathrm{m}_{P}, \mathrm{CaC}_{2} \mathrm{O}_{4}}(\%)$ for all examined calcification thicknesses ranged from: (i) 2.07 to $19.51 \%$ for $4.2 \mathrm{~cm}$, (ii) 2.27 to $21.28 \%$ for $5 \mathrm{~cm}$, and (iii) 2.56 to $23.78 \%$ for $6 \mathrm{~cm}$.

Table 3. Overlap area-OA (\%), false negative-FN (\%) and false positive-FP (\%) values for indicative thicknesses for the double exposure technique.

\begin{tabular}{|c|c|c|c|c|c|c|c|c|c|c|}
\hline \multirow[b]{2}{*}{ Case } & \multirow[b]{2}{*}{$\begin{array}{c}\mathbf{t}_{\mathrm{HAp}} \\
(\mu \mathrm{m})\end{array}$} & \multicolumn{3}{|c|}{$\mathrm{T}=4.2 \mathrm{~cm}$} & \multicolumn{3}{|c|}{$T=5 \mathrm{~cm}$} & \multicolumn{3}{|c|}{$T=6 \mathrm{~cm}$} \\
\hline & & $\begin{array}{l}\text { OA } \\
(\%)\end{array}$ & $\begin{array}{l}\mathbf{F N} \\
(\%)\end{array}$ & $\begin{array}{c}\text { FP } \\
(\%)\end{array}$ & $\begin{array}{l}\text { OA } \\
(\%)\end{array}$ & $\begin{array}{l}\text { FN } \\
(\%)\end{array}$ & $\begin{array}{l}\text { FP } \\
(\%)\end{array}$ & $\begin{array}{l}\text { OA } \\
(\%)\end{array}$ & $\begin{array}{l}\text { FN } \\
(\%)\end{array}$ & $\begin{array}{l}\text { FP } \\
(\%)\end{array}$ \\
\hline \multirow{5}{*}{$\begin{array}{l}\mathrm{HAp} ; \\
\mathrm{CaCO}_{3}\end{array}$} & 100 & 59.52 & 30.59 & 28.93 & 81.34 & 15.36 & 65.98 & 97.81 & 5.78 & 92.03 \\
\hline & 300 & 2.15 & 5.91 & 6.24 & 15.05 & 7.58 & 7.47 & 20.22 & 10.18 & 10.04 \\
\hline & 500 & 0.90 & 0.37 & 0.53 & 1.53 & 0.77 & 0.76 & 3.54 & 1.79 & 1.75 \\
\hline & & & 0.00 & 0.00 & 0.00 & 0.00 & 0.00 & 0.27 & 0.17 & 0.10 \\
\hline & 900 & 0.00 & 0.00 & 0.00 & 0.00 & 0.00 & 0.00 & 0.00 & 0.00 & 0.00 \\
\hline \multirow{5}{*}{$\begin{array}{r}\mathrm{HAp} ; \\
\mathrm{CaC}_{2} \mathrm{O}_{4}\end{array}$} & 100 & 42.07 & 20.86 & 21.21 & 52.08 & 21.18 & 30.90 & 91.55 & 26.33 & 65.22 \\
\hline & 300 & 2.12 & 1.07 & 1.05 & 2.88 & 1.54 & 1.34 & 5.44 & 2.53 & 2.91 \\
\hline & 500 & 0.00 & 0.00 & 0.00 & 0.01 & 0.00 & 0.01 & 0.05 & 0.02 & 0.03 \\
\hline & 700 & 0.00 & 0.00 & 0.00 & 0.00 & 0.00 & 0.00 & 0.00 & 0.00 & 0.00 \\
\hline & 900 & 0.00 & 0.00 & 0.00 & 0.00 & 0.00 & 0.00 & 0.00 & 0.00 & 0.00 \\
\hline
\end{tabular}

3.2. Experimental evaluation of the method

3.2.1. Single exposure technique 
The averaged $\mathrm{m}_{\mathrm{Ca}} / \mathrm{m}_{\mathrm{P}}$ values for all thicknesses, the $C V_{m_{C a} / m_{P}, \text { meas }}(\%)$ and the results of Mann Whitney U test, for the examined calcification types and thicknesses are shown in table 4. The critical U value was 23 in all cases (Milton 1964), since each phantom was irradiated 10 times. The Mann Whitney U test showed that calcifications with thickness of $300 \mu \mathrm{m}$ HAp or higher can be characterized.

Table 4. Averaged $\mathrm{m}_{\mathrm{Ca}} / \mathrm{m}_{\mathrm{P}}$ for all thicknesses, $C V_{m_{C a} / m_{P}, \text { meas }}(\%)$ and Mann Whitney $\mathrm{U}$ test results of calcification phantoms for the single exposure technique.

\begin{tabular}{|c|c|c|c|c|c|c|c|c|c|}
\hline \multirow{3}{*}{$\begin{array}{l}\mathbf{t}_{\mathrm{HAp}} \\
(\mu \mathrm{m})\end{array}$} & \multicolumn{3}{|c|}{$\mathrm{m}_{\mathrm{Ca}} / \mathrm{m}_{\mathrm{P}}$} & \multirow{2}{*}{\multicolumn{3}{|c|}{$\mathrm{CV}_{\mathrm{mCa} / \mathrm{mP}, \text { meas }}(\%)$}} & \multicolumn{3}{|c|}{ Mann Whitney U test } \\
\hline & \multirow[b]{2}{*}{ HAp } & \multirow[b]{2}{*}{$\mathrm{CaCO}_{3}$} & \multirow[b]{2}{*}{$\mathrm{CaC}_{2} \mathrm{O}_{4}$} & & & & \multicolumn{2}{|r|}{ U value } & \multirow[b]{2}{*}{$\begin{array}{c}\text { Critical } \\
\text { value }\end{array}$} \\
\hline & & & & HAp & $\mathrm{CaCO}_{3}$ & $\mathrm{CaC}_{2} \mathrm{O}_{4}$ & $\begin{array}{l}\text { HAp; } \\
\mathrm{CaCO}_{3}\end{array}$ & $\begin{array}{r}\text { HAp; } \\
\mathrm{CaC}_{2} \mathrm{O}_{4}\end{array}$ & \\
\hline 300 & \multirow{4}{*}{1.58} & \multirow{4}{*}{1.31} & \multirow{4}{*}{0.75} & 13.99 & 16.59 & 9.05 & 18 & 0 & 23 \\
\hline 500 & & & & 12.51 & 8.71 & 11.13 & 16 & 0 & 23 \\
\hline 700 & & & & 13.67 & 9.44 & 1251 & 13 & 0 & 23 \\
\hline 900 & & & & 11.72 & 8.47 & 5.93 & 2 & 0 & 23 \\
\hline
\end{tabular}

In figure 13 the averaged $\mathrm{m}_{\mathrm{Ca}} / \mathrm{m}_{\mathrm{P}}$ values and the corresponding error bars are plotted, obtained from the simulation study and the experimental evaluation.

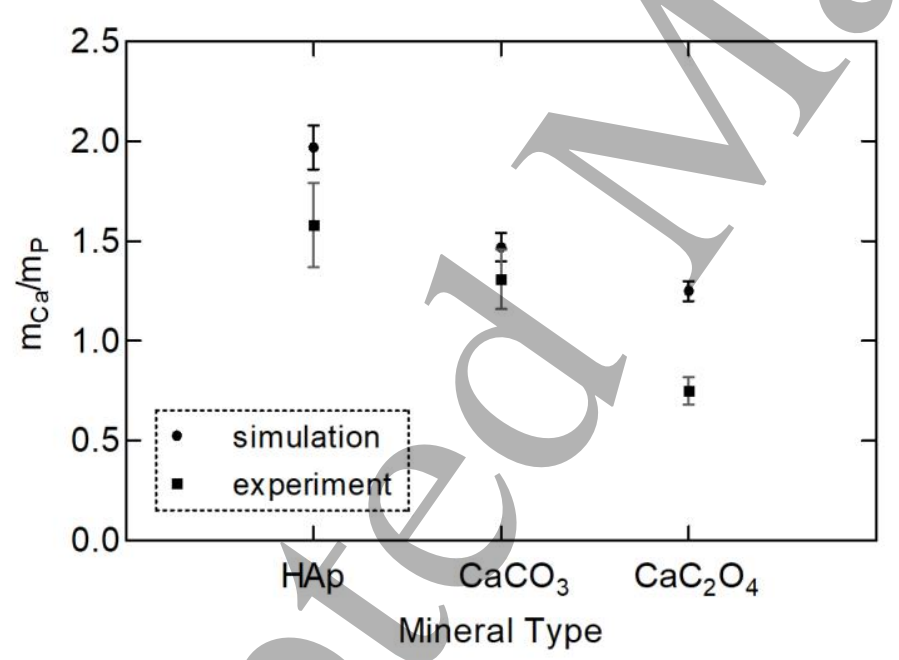

Figure 13. Averaged $\mathrm{m}_{\mathrm{Ca}} / \mathrm{m}_{\mathrm{P}}$ values obtained from simulation and experimental studies for the single exposure technique.

\subsubsection{Double exposure technique}

The averaged $\mathrm{m}_{\mathrm{Ca}} / \mathrm{m}_{\mathrm{P}}$ values for all thicknesses, the $C V_{m_{C a} / m_{P} \text {,meas }}(\%)$ of the measurements and the results of Mann Whitney U test for all calcification types, as well as, the examined thicknesses are shown in table 5. The critical $U$ value was 127 in all cases (Milton 1964), as in each phantom 20 ROIs were selected. The Mann Whitney U test concluded that calcifications of $300 \mu \mathrm{m}$ HAp thickness or higher can be characterized. 
Table 5. Averaged $\mathrm{m}_{\mathrm{Ca}} / \mathrm{m}_{\mathrm{P}}$ for all thicknesses, $C V_{m_{C a} / m_{P}, \text { meas }}(\%)$ and Mann Whitney $\mathrm{U}$ test results of calcification phantoms for the double exposure technique.

\begin{tabular}{|c|c|c|c|c|c|c|c|}
\hline \multirow{3}{*}{$\begin{array}{l}\mathbf{t}_{\text {HAp }} \\
(\mu \mathrm{m})\end{array}$} & \multicolumn{3}{|c|}{$\mathbf{m}_{\mathrm{Ca}} / \mathbf{m}_{\mathrm{P}}$} & \multicolumn{3}{|c|}{$\mathrm{CV}_{\mathrm{mCa} / \mathrm{mP}, \text { meas }}(\%)$} & \multirow{2}{*}{$\begin{array}{c}\text { Mann Whitney U test } \\
\text { U value }\end{array}$} \\
\hline & \multirow[b]{2}{*}{ HAp } & \multirow[b]{2}{*}{$\mathrm{CaCO}_{3}$} & \multirow[b]{2}{*}{$\mathrm{CaC}_{2} \mathrm{O}_{4}$} & \multirow[b]{2}{*}{ HAp } & \multirow[b]{2}{*}{$\mathrm{CaCO}_{3}$} & \multirow[b]{2}{*}{$\mathrm{CaC}_{2} \mathrm{O}_{4}$} & \\
\hline & & & & & & & $\begin{array}{ccc}\text { HAp; } & \text { HAp; } & \text { Critical } \\
\mathrm{CaCO}_{3} & \mathrm{CaC}_{2} \mathrm{O}_{4} & \text { value }\end{array}$ \\
\hline 300 & \multirow{4}{*}{1.70} & \multirow{4}{*}{1.17} & \multirow{4}{*}{1.02} & 21.29 & 22.30 & 11.04 & 127 \\
\hline 500 & & & & 19.74 & 5.48 & 5.06 & 127 \\
\hline 700 & & & & 7.04 & 19.86 & 6.79 & 127 \\
\hline 900 & & & & 5.93 & 5.75 & 5.46 & 0 \\
\hline
\end{tabular}

In figure 14 the averaged $\mathrm{m}_{\mathrm{Ca}} / \mathrm{m}_{\mathrm{P}}$ values and the corresponding error bars are plotted, obtained from the simulation study and the experimental evaluation.

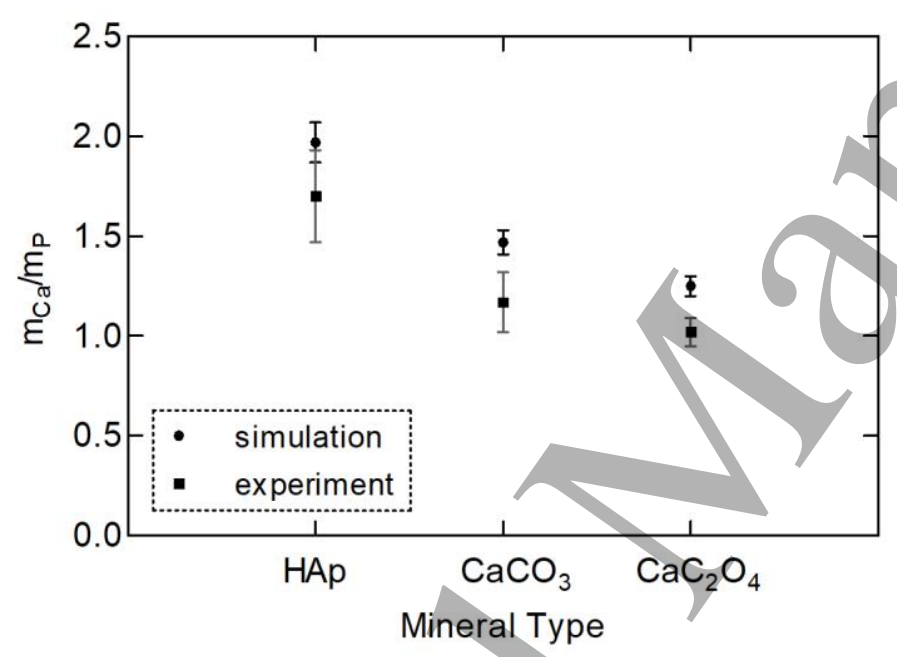

Figure 14. Averaged $\mathrm{m}_{\mathrm{Ca}} / \mathrm{m}_{\mathrm{P}}$ values obtained from simulation and experimental studies for the double exposure technique.

\section{Discussion}

In this study, a dual energy method for the characterization of calcification minerals was developed, based on the determination of the effective Calcium/Phosphorus mass ratio ( $\mathrm{m}_{\mathrm{Ca}} / \mathrm{m}_{\mathrm{P}}$ ). A simulation study was conducted, using monoenergetic beams, based on analytical modeling, in order to select the optimal low-/high-incident energies. Monochromatic beams are available from synchrotrons, which have been used in experiments for mammography in several studies demonstrating their advantages (Malliori et al 2012, Szafraniec et al 2015, Longo et al 2016). Due to the fact that in clinical practice X-ray tubes are widely used, an adjustment of the simulation study to polyenergetic spectra was conducted. Furthermore, the effect of breast thickness was examined, using the simulation study of polyenergetic X-rays. It was found that the overlap area increased, as the breast thickness increased. For instance, in the case of $\mathrm{HAp} ; \mathrm{CaCO}_{3}$ and calcification thickness of $300 \mu \mathrm{m}$ HAp, an average increase of approximately $67.69 \%$ was observed $(68.86 \%$ for the 
single exposure, $66.51 \%$ for the double exposure) by increasing the breast thickness from 4.2 to $6 \mathrm{~cm}$. However, the overlap areas will decrease by applying appropriate entrance doses to the examined breast thicknesses. This can be employed without significantly increasing the risk to the patient relating to dose considering the following procedure: (i) the clinician will be able to distinguish the calcifications that must be characterized after the low-energy irradiation, (ii) the second irradiation with the high-energy can be restricted in a small area including the calcification, resulting in reduced mean absorbed dose to the breast. These irregular shaped irradiation fields could be more accurately defined by adopting the solution of a dedicated multi-leaf collimator.

The optimized irradiation parameters obtained from the simulation study were used for the experimental evaluation of the method. Both single and double exposure techniques, were studied and applied using photon counting energy dispersive and energy integrating detector. The Mann-Whitney $U$ non-parametric statistical test was applied to the measured $\mathrm{m}_{\mathrm{Ca}} / \mathrm{m}_{\mathrm{P}}$ values and showed that there are statistically significant differences $(\mathrm{p}<0.05)$ between the calcification minerals for thicknesses of $300 \mu \mathrm{m}$ or higher, in both single and double exposure techniques. In our method, cylindrical phantoms were irradiated in the longitudinal direction where the thickness of the mineral was constant. For other shapes (spherical or ellipsoidal) a mean thickness value lower than the maximum thickness that can be reached in the beam path, must be considered.

In the polyenergetic studies, the mass attenuation coefficients were replaced by the effective mass attenuation coefficients of each spectral peak of the simulated or measured filtered spectra. The disadvantage of this approach is that neighboring energy pairs, which lead the equation system (please see Appendix A1, A2, A3) to linear dependence, are not considered in the simulation study. Furthermore, the determination of the effective mass attenuation coefficients does not take into consideration the beam hardening effect of the polyenergetic spectra. Additionally, the mass attenuation coefficient does not include the number of scattered photons that can be finally found in the beam falling on the detector. However, in both geometries of the experimental configurations (even in the pencil beam), after coherent or incoherent interactions in/matter, a number of photons can be detected. These reasons explain (i) the higher measured $C V_{m_{C a} / m_{P} \text {,meas }}(\%)$ compared to the theoretical $C V_{m_{C a} / m_{P}}(\%)$, and (ii) the systematic decrease in the $\mathrm{m}_{\mathrm{Ca}} / \mathrm{m}_{\mathrm{P}}$ values that can be observed in the experimental results compared to those obtained from the simulation, at both single and double exposure techniques. Hence, a correction factor of approximately 1.35 and 1.21 can be applied to the measured $m_{C a} / m_{P}$ values for the single and double exposure technique, respectively, improving the accuracy of the method. Furthermore, the electronic and X-ray source instability, which are not considered in the simulation study, led to the higher measured $C V_{m_{C a} / m_{P}, \text { meas }}(\%)$ compared to the theoretical $C V_{m_{C a} / m_{P}}(\%)$. Comparing the nominal $\mathrm{m}_{\mathrm{Ca}} / \mathrm{m}_{\mathrm{P}}$ value of HAp 2.15 (Sotiropoulou et al 2015) with the measured for the single 1.58 and the double 1.70 exposure technique, the calculated accuracy of the method was $26.51 \%$ and $20.93 \%$, respectively. The accuracy of the method can be improved by using a calibration procedure incorporating inverse mapping techniques (Kappadath and Shaw 2003). When polynomial nonlinear inverse functions are applied, error parameters arising from beam hardening, scatter radiation and nonlinear response of the detector, can be diminished or even eliminated (Sotiropoulou et al 2016) and will be investigated in future studies. 
In the simulation study, the total number of photons after attenuation, in the single exposure technique was $\sim 2 \times 10^{6} / 1.5 \times 10^{7}$ for the low-/high-energy, while in the double exposure technique was $\sim 3 \times 10^{6} / 1.5 \times 10^{7}$ for the low-/high-energy. For the measured data to be consistent with the simulation, the measured number of photons was $\sim 1 \times 10^{6} / 1 \times 10^{7}$ for the low-/high-energy, in the single exposure technique. The corresponding number of photons in the double exposure technique was $3 \times 10^{6} / 1.3 \times 10^{7}$ per $\mathrm{mm}^{2}$ for the low-/high-energy. The imaging detector has a pixel with an active area of $22.5 \times 22.5 \mu \mathrm{m}^{2}$, thus approximately $44 \times 44=1,936$ pixels must be used in order to obtain $1 \mathrm{~mm}^{2}$ corresponding to approximately $3 \times 10^{6}$ and $1.3 \times 10^{7}$ number of photons. The detector used has a bit depth (digital output) of 12 bits corresponding to 4,096 gray levels. Summing the events in the 1,936 number of pixels, the highest pixel value that can be achieved is $1,936 \times 4,096=7,929,856 \sim 8 \times 10^{6}$. Hence, ROIs of $44 \times 44$ pixels are adequate to obtain proper number of photons for the double exposure technique.

In commercially available clinical mammography systems the main restriction is that the $\mathrm{X}$ ray source high voltage ranges from 20 to $49 \mathrm{kV}$. The low- and high-energy, indicated by the current monoenergetic simulation study, ranges from 23 to $27 \mathrm{keV}$ and 53 to $70 \mathrm{keV}$, respectively. Thus, the adaptation of a clinical system, where the mean energy will be lower than $53 \mathrm{keV}$, will result in a $C V_{m_{C a} / m_{P}}(\%)$ higher than that of $+50 \%$ of the minimum $C V_{m_{C a} / m_{P}}(\%)$ (Fig. 6). This will increase the minimum calcification thickness that can be characterized. The majority of the installed clinical detector systems have a minimum pixel size of $70 \mu \mathrm{m}$ with a bit depth up to 14 bits corresponding to 16,384 gray levels. In order to characterize the mineral types, a number of photons of about $10^{7}$ are essential. Summing the events in 225 number of pixels (ROI of $15 \times 15$ pixels in order to obtain $1 \mathrm{~mm}^{2}$ ), the highest pixel value that can be achieved is $225 \times 16,384=3,686,400 \sim 3.7 \times 10^{6}$. Comparing this value with that of the detector used, only the half pixel values per area can be obtained from a detector of a clinical system.

A clinical system appropriate for this method would be a mammography system with W anode, high voltage generator ranging from 25 to $70 \mathrm{kV}$ and a detector system with a combination of pixel size and depth capable of registering $10^{7}$ photons per calcification area. For instance, if a calcification of $350 \mu \mathrm{m}$ must be characterized and the pixel size is $70 \mu \mathrm{m}$, the calcification will be spanned across $5 \times 5=25$ pixels. These pixels must be able to register $10^{7}$ photons or $4 \times 10^{5}$ photons/pixel. In order to achieve that, a bit depth of 19 $\left(\log _{2}\left(4 \times 10^{5}\right)=18.61\right)$ is required. To summarize, the required bit depth $\left(R_{b i t}\right)$ can be expressed as $R_{b i t}=\log _{2}(I \cdot P A / C A)$, where $I$ is the required number of photons, $P A$ and $C A$ are the pixel and the calcification area, respectively.

The dual energy method implemented in this work discriminates calcifications thicker than $300 \mu \mathrm{m}$, mainly due to the statistical noise which depends on the final detected number of photons. In breast, small/microcalcification clusters, which are important for malignancy diagnosis, consist of numerous calcifications. If microcalcifications inside the cluster are thinner than $300 \mu \mathrm{m}$, ROIs on the calcifications can be selected. By summing the corresponding photons from each ROI, the total number of photons will be increased potentially allowing the characterization of microcalcifications in the cluster. In future work, phantoms simulating realistic breast will be constructed using inhomogeneous breast tissue equivalent materials and calcifications with smaller sizes. 


\section{Conclusions}

We proposed a dual energy method for the characterization of minerals associated with pathogenesis. The presented analytical model uses monoenergetic and polyenergetic X-ray beams to determine the $\mathrm{m}_{\mathrm{Ca}} / \mathrm{m}_{\mathrm{P}}$. The effective $\mathrm{m}_{\mathrm{Ca}} / \mathrm{m}_{\mathrm{P}}$ is calculated for three calcification minerals, indicating malignancy (HAp) and benignancy $\left(\mathrm{CaCO}_{3}, \mathrm{CaC}_{2} \mathrm{O}_{4}\right)$. The experimental evaluation of the method revealed that calcifications of $300 \mu \mathrm{m} \mathrm{HAp}$, and the corresponding calcification thicknesses for $\mathrm{CaCO}_{3}$ and $\mathrm{CaC}_{2} \mathrm{O}_{4}$, or higher can be characterized. Further studies will indicate the potential of the method to provide in-vivo information about the minerals avoiding invasive diagnostic methods such as biopsy.

\section{Acknowledgements}

The authors wish to thank Mr. I. Ntinos for his general statistical consulting. This work was supported by Grant E.040 from the Research Committee of the University of Patras (Programme K. Karatheodori).

\section{Appendix: $\mathbf{C a} / \mathbf{P}$ mass ratio determination}

Consider that along the radiation path, three major components can be regarded as attenuators: calcium-Ca, phosphate- $\mathrm{PO}_{4}$ and breast tissue. The total thickness- $\mathrm{T}(\mathrm{cm})$ is given by:

$$
T=t_{C a}+t_{P O_{4}}+t_{b}
$$

where, $t_{C a}, t_{P_{4}}, t_{b}$ are the thicknesses of calcium, phosphate and breast tissue respectively. Using two monoenergetic X-rays, for the low- (l) and high-energy (h), and accepting an exponential attenuation of both X-rays, then the intensities with only the breast tissue in the radiation path (where $t_{b}=T$ ) can be obtained by:

$$
I_{b, E_{i}}=I_{o, E_{i}} e^{-\mu_{b, E_{i} T}} \quad i=l, h
$$

where, $I_{o, E_{i}}$ is the unattenuated intensity for the low- and high-energy, $\mu_{b, E_{i}}$ is the energydepended linear attenuation coefficient $(1 / \mathrm{cm})$ for breast tissue composed of $50 \%$ adipose and $50 \%$ glandular tissue $\left(0.5 \mu_{a, E_{i}}+0.5 \mu_{g, E_{i}}\right)$ and $\mathrm{T}$ is the total thickness (cm).

Respectively, when the three materials are present, the attenuated intensities for the low- and high-energy are given by:

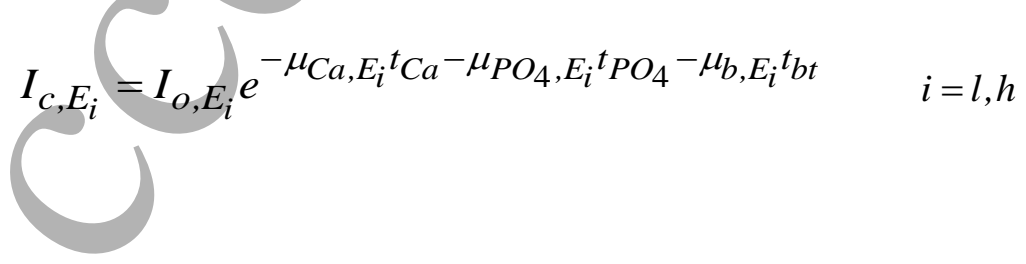


where, $I_{o, E_{i}}$ is the unattenuated intensity for the low- and high-energy and $\mu_{C a, E_{i}}, \mu_{P_{4}, E_{i}}$, $\mu_{b, E_{i}}$ are the energy-depended linear attenuation coefficients $(1 / \mathrm{cm})$ for calcium, phosphate and breast tissue, respectively.

Defining, $\Delta \mu_{C a, E_{i}}=\left(\mu_{C a, E_{i}}-\mu_{b, E_{i}}\right)$ and $\Delta \mu_{P O_{4}, E_{i}}=\left(\mu_{P O_{4}, E_{i}}-\mu_{b, E_{i}}\right)$, solving for $t_{b}$ in Eq. A1 and replace in Eq. A3, the low- and high-energy intensities can be rewritten as:

$$
I_{c, E_{i}}=I_{o, E_{i}} e^{-\Delta \mu_{C a, E_{i}}{ }_{C a}-\Delta \mu_{P O_{4}, E_{i}}{ }_{P O} O_{4}-\mu_{b, E_{i}} T} \quad i=l, h
$$

The X-ray densities are defined as the logarithmic transform of Eqs. A2, A4 (Fountos et al 1997, Lemacks et al 2002):

$$
\begin{aligned}
& Y_{E_{i}}=\ln \left(\frac{I_{b, E_{i}}}{I_{c, E_{i}}}\right)=\ln \left(\frac{I_{o, E_{i}} e^{-\mu_{b, E_{i} T} T}}{\left.I_{o, E_{i}} e^{-\Delta \mu_{C a, E_{i}}{ }_{C a}-\Delta \mu_{P O_{4}, E_{i} t_{P O_{4}}-\mu_{b, E_{i} T}}}\right)}\right) \ln \left(e^{\left.\Delta \mu_{C a, E_{i} t_{C a}+\Delta \mu_{P O_{4}, E_{i}} t_{P O_{4}}}\right)}\right. \\
& i=l, h
\end{aligned}
$$

Finally, X-ray densities for the low- and high-energy, are a linear function of thicknesses $t_{C a}$ and $t_{P O_{4}}$ :

$$
\begin{gathered}
Y_{E_{l}}=\Delta \mu_{C a, E_{l}} t_{C a}+\Delta \mu_{P O_{4}, E_{l}} t_{P O_{4}} \\
Y_{E_{h}}=\Delta \mu_{C a, E_{h}}{ }_{C a}+\Delta \mu_{P O_{4}, E_{h}} t_{P O_{4}}
\end{gathered}
$$

The two equations above form a linear system of two equations with two unknown variables ${ }^{t}{ }_{\mathrm{Ca}}$ and $t_{\mathrm{PO}_{4}}$ ). The two thicknesses are obtained by solving the linear system of Eqs. A6a, A6b with Cramer's rule using the determinants:

$$
\begin{aligned}
& D=\left(\begin{array}{ll}
\Delta \mu_{C a, E_{l}} & \Delta \mu_{P O_{4}, E_{l}} \\
\Delta \mu_{C a, E_{h}} & \Delta \mu_{P O_{4}, E_{h}}
\end{array}\right)=\Delta \mu_{C a, E_{l}} \Delta \mu_{P O_{4}, E_{h}}-\Delta \mu_{C a, E_{h}} \Delta \mu_{P O_{4}, E_{l}} \\
& D_{t_{C a}}=\left(\begin{array}{cc}
Y_{E_{l}} & \Delta \mu_{P O_{4}, E_{l}} \\
Y_{E_{h}} & \Delta \mu_{P O_{4}, E_{h}}
\end{array}\right)=Y_{E_{l}} \Delta \mu_{P O_{4}, E_{h}}-Y_{E_{h}} \Delta \mu_{P O_{4}, E_{l}} \\
& D_{t_{P O_{4}}}=\left(\begin{array}{cc}
\Delta \mu_{C a, E_{l}} & Y_{E_{l}} \\
\Delta \mu_{C a, E_{h}} & Y_{E_{h}}
\end{array}\right)=Y_{E_{h}} \Delta \mu_{C a, E_{l}}-Y_{E_{l}} \Delta \mu_{C a, E_{h}}
\end{aligned}
$$

The thicknesses $t_{\mathrm{Ca}}$ and $t_{\mathrm{PO}_{4}}$ are calculated by: 


$$
\begin{gathered}
t_{C a}=\frac{D_{t_{C a}}}{D} \\
t_{P_{4}}=\frac{D_{t_{P O_{4}}}}{D}
\end{gathered}
$$

From Eqs. A10a, A10b, substituting from A7, A8, A9 we obtain the ratio:

$$
\frac{t_{C a}}{t_{P O_{4}}}=\frac{Y_{E_{l}} \Delta \mu_{P O_{4}, E_{h}}-Y_{E_{h}} \Delta \mu_{P O_{4}, E_{l}}}{Y_{E_{h}} \Delta \mu_{C a, E_{l}}-Y_{E_{l}} \Delta \mu_{C a, E_{h}}}
$$

If $\rho_{\mathrm{CaPO}_{4}}$ is the density of $\mathrm{Ca}_{10-\mathrm{x}}\left(\mathrm{PO}_{4}\right)_{6}$ and $\rho_{\mathrm{Ca}}, \rho_{\mathrm{PO}_{4}}, m_{\mathrm{Ca}}, m_{\mathrm{PO}_{4}}$ are the densities and masses of $\mathrm{Ca}$ and $\mathrm{PO}_{4}$ respectively, then

$\rho_{\mathrm{CaPO}_{4}}=\frac{\left(m_{\mathrm{Ca}}+m_{\mathrm{PO}_{4}}\right) \rho_{\mathrm{Ca}_{2} \rho_{\mathrm{PO}_{4}}}}{m_{\mathrm{Ca}} \rho_{\mathrm{PO}_{4}}+m_{\mathrm{PO}_{4}} \rho_{\mathrm{Ca}}}$

where the volume that $m$ specifies is the volume of the beam inside the material.

$\frac{V_{C a}}{V_{P O_{4}}}=\frac{m_{C a} / \rho_{C a}}{m_{P O_{4}} / \rho_{P O_{4}}}=\frac{m_{C a} \rho_{P O_{4}}}{m_{P O_{4}} \rho_{C a}}$

where $V_{C a}, V_{P_{4}}$ are the volumes of $\mathrm{Ca}$ and $\mathrm{PO}_{4}$ exposed to the beam.

But $V_{C a}=S_{C a} t_{C a}$ (A14) and $V_{P_{4}}=S_{P_{4}} t_{P O_{4}}$ (A15) where $S_{C a}, S_{P O_{4}}$ are the surfaces of $\mathrm{Ca}$ and $\mathrm{PO}_{4}$ exposed to the beam. From Eqs. A13, A14 and A15 $\frac{S_{C a} t_{C a}}{S_{P_{4}} t_{P O_{4}}}=\frac{m_{C a} \rho_{P O_{4}}}{m_{P O_{4}} \rho_{C a}}$ (A16), where $S_{C a}=S_{P_{4}}$ since both surfaces are exposed to the same beam. Finally, $\frac{t_{C a}}{t_{P O_{4}}}=\frac{m_{C a} \rho_{P O_{4}}}{m_{P O_{4}} \rho_{C a}}(\mathrm{~A} 17)$. Because the molecular weight ratio $\left(P_{4} / P=3.0679\right)$, the weight ratio is given by $\frac{m_{C a}}{m_{P}}=\frac{m_{C a}}{m_{P O_{4}}} 3.0679$ (A18) (Fountos et al 1997). Combining Eqs. A11, A12, A17 and A18:

$$
\frac{m_{C a}}{m_{P}}=\frac{Y_{E_{l}} \Delta \mu_{P O_{4}, E_{h}}-Y_{E_{h}} \Delta \mu_{P O_{4}, E_{l}}}{Y_{E_{h}} \Delta \mu_{C a, E_{l}}-Y_{E_{l}} \Delta \mu_{C a, E_{h}}} 3.0679
$$


The standard deviation in $\mathrm{m}_{\mathrm{Ca}} / \mathrm{m}_{\mathrm{P}}$ is obtained by partial differentiation of Eq. A19, assuming Poisson distribution for the incident beam. Therefore the coefficient of variation $(\mathrm{CV}), C V_{m_{C a} / m_{P}}(\%)=\left(S D_{m_{C a} / m_{P}} / m_{m_{C a} / m_{P}}\right) 100$, derives from:
$C V_{m_{C a} / m_{P}}^{2}=\left(\frac{1}{I_{b, E_{l}}}+\frac{1}{I_{c, E_{l}}}\right)\left(\frac{\left(\Delta \mu_{P O_{4}, E_{h}}\right)^{2}}{\left(Y_{E_{l}} \Delta \mu_{P O_{4}, E_{h}}-Y_{E_{h}} \Delta \mu_{P O_{4}, E_{l}}\right)^{2}}+\frac{\left(\Delta \mu_{C a, E_{h}}\right)^{2}}{\left(Y_{E_{h}} \Delta \mu_{C a, E_{l}}-Y_{E_{l}} \Delta \mu_{C a, E_{h}}\right)^{2}}\right) 100^{2}$
$+\left(\frac{1}{I_{b, E_{h}}}+\frac{1}{I_{C, E_{h}}}\right)\left(\frac{\left(\Delta \mu_{P O_{4}, E_{l}}\right)^{2}}{\left(Y_{E_{l}} \Delta \mu_{P O_{4}, E_{h}}-Y_{E_{h}} \Delta \mu_{P O_{4}, E_{l}}\right)^{2}}+\frac{\left.\left(\Delta \mu_{C a, E_{l}}\right)^{2}\right)}{\left(Y_{E_{h}} \Delta \mu_{C a, E_{l}}-Y_{E_{l}} \Delta \mu_{C a, E_{h}}\right)^{2}}\right) 100^{2}$

(A20)

In order to obtain the linear attenuation coefficients used in the above equations, the mass attenuation coefficients $(\mu / \rho)$ were multiplied by the density $(\rho)$ of the appropriate material. The density values of adipose- $0.93 \mathrm{~g} / \mathrm{cm}^{3}$ and glandular $-1.04 \mathrm{~g} / \mathrm{cm}^{3}$ tissue (which compose the breast tissue) were obtained from published data (Hammerstein et al 1979). Since the main mass in hydroxyapatite molecules is $\mathrm{Ca}_{10-\mathrm{x}}\left(\mathrm{PO}_{4}\right)_{6}$, instead of $\rho_{\mathrm{CaPO}_{4}}$, the density of hydroxyapatite (bone ash) $3.18 \mathrm{~g} / \mathrm{cm}^{3}$ can be used (Fountos et al 1997).

\section{References}

American College of Radiology. ACR practice guideline for the performance of screening mammography. Reston, VA: American College of Radiology 2006 217-225

Baker R, Matousek P, Ronayne K L, Parker A W, Rogers K and Stone N 2007 Depth profiling of calcifications in breast tissue using picosecond Kerr-gated Raman spectroscopy Analyst 132 48-53

Baker R, Rogers K D, Shepherd N and Stone N 2010 New relationships between breast microcalcifications and cancer Br. J. Cancer. 103 1034-1039

Boone J M and Seibert J A 1997 An accurate method for computer-generating tungsten anode X-ray spectra from 30 to $140 \mathrm{kV}$ Med. Phys. 24 1661-1670

Bowman A W and Azzalini A 1997 Applied Smoothing Techniques for Data Analysis New York: Oxford University Press Inc.

Brandan M and Ramirez V 2006 Evaluation of dual energy subtraction of digital mammography images under conditions found in a commercial unit Phys. Med. Biol. 51 2307-2320

Busing C M, Keppler U and Menges V 1981 Differences in microcalcification in breast tumors Virchows Arch. [Pathol Anat] 393 307-313

Byng J W, Mainprize J G and Yaffe M J 1998 X-ray characterization of breast phantom materials Phys. Med. Biol. 43 1367-1377

Chen X, Mou X and Zhang L 2008 Indicator and Calibration Material for Microcalcification in Dual-energy Mammography Medical Biometrics $7^{\text {th }}$ International Conference (ICMB 2008, Hong Kong, China) Lecture Notes in Computer Science 4901 265-272 
Chen X, Nishikawa R M, Chan S, Lau B A, Zhang L and Mou X 2013 Algorithmic scatter correction in dual-energy digital mammography Med. Phys. 40111919

Cox RF and Morgan P 2013 Microcalcifications in breast cancer: Lessons from physiological mineralization Bone $\mathbf{5 3}$ 437-450

Del Lama L S, Cunha D M and Poletti M E 2016 Validation of a modified PENELOPE Monte Carlo code for applications in digital and dual energy mammography. Radiat. Phys. Chem. http://dx.doi.org/10.1016/j.radphyschem.2016.03.004.

Del Lama L S, Godeli J and Poletti M E 2016a Monte Carlo simulation studies for the determination of microcalcification thickness and glandular ratio through dual energy mammography. Radiat. Phys. Chem. http://dx.doi.org/10.1016/j.radphyschem. 2016.02.005.

Del Medical Systems Group, Roselle, IL [Online]. Available from: http://www.delmedical.com.

European Commission (EC). Diagnostic Reference Levels in Thirty-six European Countries, Radiation Protection 180, Part 2, 2014.

Fandos-Morera A, Prats-Esteve M, Tura-Soteras J and Traveria-Cros A 1988 Breast tumors: Composition of microcalcifications Radiology 169 325-327

Fountos G, Yasumura S and Glaros D 1997. The skeletal calcium/phosphorus ratio: A new in vivo method of determination Med. Phys. 24 1303-1310

Frappart L et al 1984. Structure and composition of microcalcifications in benign and malignant lesions of the breast: study by light microscopy, microprobe analysis, and X-ray diffraction Hum. Pathol. 15 880-889

Frappart L, Remy I, Lin HC, Bremond A, Raudrant D, Grousson B and Vauzelle JL 1986 Different types of microcalcifications observed in breast pathology Virchows Arch. A. 410 179-187

Gong J K, Arnold J S and Cohn S H 1964 The density of organic and volatile and non volatile inorganic components of bone Anatom. Rec. 149 319-324

Haka A S, Shafer-Peltier K E, Fitzmaurice M, Crowe J, Dasari R R and Feld M S 2002 Identifying microcalcifications in benign and malignant breast lesions by probing differences in their chemical composition using Raman spectroscopy Clin. Cancer Res. 62 5375-5380

Hammerstein G, Miller D, White D, Masterson M, Woodard H and Laughlin J 1979 Absorbed radiation dose in mammography Radiology 130 485-491

Hubbell J H and Seltzer S M 1996 Tables of X-ray mass attenuation coefficients and mass energy absorption coefficients $1 \mathrm{keV}$ to $20 \mathrm{MeV}$ for elements $\mathrm{Z}=1$ to 92 and 48 additional substances of dosimetric interest. US Department of commerce NISTIR, 5632

Johns P C and Yaffe M J 1987 X-ray characterization of normal and neoplastic breast tissues Phys. Med. Biol. 32 675-695

Jones M C, Marron J S and Sheather S J 1996 A Brief Survey of Bandwidth Selection for Density Estimation J. Am. Stat. Assoc. 91 401-407

Kappadath S C and Shaw C C 2003 Dual-energy digital mammography: Calibration and inverse-mapping techniques to estimate calcification thickness and glandular-tissue ratio Med. Phys. 30 1110-1117

Kappadath S C and Shaw C C 2004 Quantitative evaluation of dual-energy digital mammography for calcification imaging Phys. Med. Biol. 49 2563-2576

Kappadath S C and Shaw C C 2005 Dual-energy digital mammography for calcification imaging: Scatter and nonuniformity corrections Med. Phys. 32 3395-3408 
Kappadath S C and Shaw C C 2008 Dual-energy digital mammography for calcification imaging: noise reduction techniques Phys. Med. Biol. 53 5421-5443

Kerssens M M, Matousek P, Rogers K and Stone N 2010 Towards a safe non-invasive method for evaluation the carbonate substitution levels of hydroxyapatite (HAP) in microcalcifications found in breast tissue Analyst 135 3156-3161

Koukou V, Martini N, Michail C, Sotiropoulou P, Fountzoula C, Kalyvas N, Kandarakis I, Nikiforidis G and Fountos G 2015 Dual energy method for breast imaging: A simulation study Comput. Math. Methods Med. 574238

Koukou V, Martini N, Fountos G, Michail C, Bakas A, Oikonomou G, Kandarakis I and Nikiforidis G 2017 Application of a dual energy X-ray imaging method on breast specimen Results in Physics 7 1634-1636

Koukou V, Martini N, Fountos G, Michail C, Sotiropoulou P, Bakas A, Kalyvas N, Kandarakis I, Speller D and Nikiforidis G 2017a Dual energy subtraction method for breast calcification imaging Nucl. Instrum. Meth. Phys. Res. A $84831-38$

Leborgne R 1951 Diagnosis of tumors of the breast by simple roentgenography; Calcifications in carcinomas Am. J. Roentgenol. Radium Ther. Nucl. Med. 65 1-11

Lemacks M R, Kappadath S C, Shaw C C, Liu X and Whitman G J 2002 A dual-energy subtraction technique for microcalcification imaging in dígital mammography- A signalto-noise analysis Med. Phys. 29 1739-1751

Longo R et al 2016 Towards breast tomography with synchrotron radiation at Elettra: first images Phys. Med. Biol. 61 1634-1649

Malliori A, Bliznakova K, Speller R D, Horrocks J A, Rigon L, Tromba G and Pallikarakis N 2012 Image quality evaluation of breast tomosynthesis with synchrotron radiation Med. Phys. 39 5621-5634

Martini N, Koukou V, Michail C, Sotiropoulou P, Kalyvas N, Kandarakis I, Nikiforidis G and Fountos G 2015 Pencil beam spectral measurements of $\mathrm{Ce}$, Ho, Yb, and Ba powders for potential use in medical applications J. of Spectroscopy. 563763

Matousek P and Stone N 2007 Prospects for the diagnosis of breast cancer by noninvasive probing of calcifications using transmission Raman spectroscopy J. Biomed. Opt. 12 024008

Matousek P and Stone N 2013 Recent advances in the development of Raman spectroscopy for deep non-invasive medical diagnosis J. Biophotonics. 6 7-19

Michail C, Fountos G, Valais I, Kalyvas N, Liaparinos P, Kandarakis I and Panayiotakis G 2011a Evaluation of the red emitting $\mathrm{Gd}_{2} \mathrm{O}_{2} \mathrm{~S}$ :Eu powder scintillator for use in indirect $\mathrm{X}$ ray digital mammography detectors IEEE Trans. Nucl. Sci. $\mathbf{5 8}$ 2503-2511

Michail C, Spyropoulou V, Fountos G, Kalyvas N, Valais I, Kandarakis I and Panayiotakis G 2011b Experimental and theoretical evaluation of a high resolution CMOS based detector under X-ray imaging conditions IEEE Trans. Nucl. Sci. 58 314-322

Milton R C 1964 An extended table of critical values for the Mann-Whitney (Wilcoxon) twosample statistic J. Amer. Statist. Assoc. 59 925-934

Morgan M P, Cooke M M and McCarthy G M 2005 Microcalcifications Associated with Breast Cancer: An Epiphenomenon or Biologically Significant Feature of Selected Tumors? J. Mammary Gland. Biol. Neoplasia 10 181-187

Morgan M P, Cooke M M, Christopherson P A, Westfall P R and McCarthy G M 2001 Calcium hydroxyapatite promotes mitogenesis and matrix metalloproteinase expression in human breast cancer cell lines Mol. Carcinog. 32 111-117 
Radi M J 1989 Calcium oxalate crystals in breast biopsies. An overlooked form of microcalcification associated with benign breast disease Arch. Pathol. Lab. Med. 113 1367-1369

Roberts M, Kahn E and Haddawy P 1995 Development of a Bayesian network for diagnosis of breast cancer IJCAI-95 Workshop on Building Probabilistic Networks

Sorenson J A, Duke P R and Smith S W 1989 Simulation studies of dual-energy x-ray absorptiometry Med. Phys. 16 75-80

Sotiropoulou P, Fountos G, Martini N, Koukou V, Michail C, Kandarakis I and Nikiforidis G 2015 Bone calcium/phosphorus ratio determination using dual energy X-ray method Phys. Medica 31 307-313

Sotiropoulou P, Fountos G, Martini N, Koukou V, Michail C, Kandarakis I and Nikiforidis G 2016 Polynomial dual energy inverse functions for bone Calcium/Phosphorus ratio determination and experimental evaluation Appl. Radiat. Isot. 118 18-24

Stone N and Matousek P 2008 Advanced transmission Raman spectroscopy: a promising tool for breast disease diagnosis Cancer Res. 68 4424-4430

Stone N, Baker R, Rogers K, Parker A W and Matousek P 2007 Subsurface probing of calcifications with spatially offset Raman spectroscopy (SORS): future possibilities for the diagnosis of breast cancer Analyst 132 899-905

Szafraniec M B et al 2015 Synchrotron based planar imaging and digital tomosynthesis of breast and biopsy phantoms using a CMOS active pixel sensor. Phys. Medica 31 192-198

Taibi A, Fabbri S, Baldelli P, di Maggio C, Gennaro G, Marziani M, Tuffanelli A and Gambaccini M 2003 Dual-energy imaging in full-field digital mammography: a phantom study Phys. Med. Biol. 48 1945-1956

Wang Z, Hauser N, Singer G, Trippel M, Kubik-Huch R A, Chneider C W and Stampanoni M 2014 Non-invasive classification of microcalcifications with phase-contrast X-ray mammography Nat. Commun. 5 1-9

Warren L M, Mackenzie A, Dance D R and Young K C 2013 Comparison of the x-ray attenuation properties of breast calcifications, aluminum, hydroxyapatite and calcium oxalate Phys. Med. Biol. 58 N103-N113

World Health Organization. World Health Statistics 2008; 2008 